\title{
Initial backscatter occurrence statistics from the CUTLASS HF radars
}

\author{
S. E. Milan, T. K. Yeoman, M. Lester, E. C. Thomas, T. B. Jones \\ Department of Physics and Astronomy, University of Leicester, Leicester, LE1 7RH, UK
}

Received: 30 September 1995 / Revised: 16 January 1997 / Accepted: 28 January 1997

\begin{abstract}
A statistical study of the occurrence of ground and ionospheric backscatter within the fields-of-view of the CUTLASS HF radars, at an operating frequency of $10 \mathrm{MHz}$, during the first 20 months of operation has been undertaken. The diurnal variation of the occurrence of backscatter and the range at which such backscatter is observed is found to be highly dependent on seasonal changes of the ionospheric electron density in both the $\mathrm{E}$ and $\mathrm{F}$ region, determined from ionosonde observations. In general, ionospheric backscatter is observed at far ranges during the local day in winter months and at near ranges during the local night in summer months. The Iceland radar observes more nearrange $\mathrm{E}$ region backscatter than the Finland radar as a consequence of its more zonal look-direction. The dependence of the occurrence of backscatter on geomagnetic activity and radar operating frequency are also investigated. The occurrence of ground and ionospheric backscatter is discussed in terms of $\mathrm{HF}$ propagation modes and ionospheric electron densities as well as geophysical processes. A brief assessment of the possible impact of solar cycle variations on the observations is made and frequency management is discussed. Such a study, with its focus on the 'instrumental' aspect of backscatter occurrence, is essential for a full interpretation of $\mathrm{HF}$ coherent radar observations.
\end{abstract}

\section{Introduction}

The SuperDARN coherent HF radars (Greenwald et al., 1995) are designed to employ backscatter from highlatitude field-aligned ionospheric plasma density irregularities (radar aurora) as tracers of the bulk plasma motion under the influence of the convection electric field, and hence as a diagnostic tool for the investigation

Correspondence to: S. E. Milan of large-scale magnetospheric-ionospheric coupling. The Co-operative UK Twin Located Auroral Sounding System (CUTLASS) forms the eastern-most pair of radars of SuperDARN, and is the focus of the present study.

Backscatter of the radar radio wave, $\mathbf{k}_{\mathrm{r}}$, occurs from ionospheric irregularities with wave vectors, $\mathbf{k}$, which satisfy the Bragg condition $\mathbf{k}= \pm 2 \mathbf{k}_{\mathrm{r}}$. The field-aligned nature of the irregularities $(\mathbf{k} \perp \mathbf{B}$, where $\mathbf{B}$ is the magnetic field) requires that the radar wave vector is orthogonal to the local magnetic field $\left(\mathbf{k}_{\mathrm{r}} \perp \mathbf{B}\right)$ at the point of scatter for the return wave vector to be incident on the radar and coherent backscatter to be observed. The advantage of HF radars over VHF radars, which were previously employed for convection studies (e.g. Greenwald et al., 1978; Nielsen et al., 1983a), is their ability to achieve the orthogonality condition with the magnetic field in the $F$ region as well as the E region due to the refractive nature of radio wave propagation in the $3 \mathrm{MHz}$ to $30 \mathrm{MHz}$ frequency band (for a comprehensive discussion of HF propagation see Davies, 1990). Figure 1 presents schematically some of the possible propagation modes by which backscatter information can be returned to an $\mathrm{HF}$ radar located near auroral latitudes and pointing polewards. Backscatter originates where $\mathbf{k}_{\mathrm{r}}$ approaches orthogonality with the magnetic field $\mathbf{B}$, in the case of ionospheric backscatter, or at ground reflections in the case of ground backscatter. The nomenclature for HF propagation was originally developed for point to point communications between ground stations and hence whole hops (propagation from ground to ionospheric reflection point to ground) are labelled with integer numbers and a letter denoting the reflecting layer, e.g. 1F. Ground backscatter from this point of ground incidence is then termed $1 \mathrm{~F}$ backscatter. As ionospheric backscatter originates between points of ground incidence it is labelled as integerand-a-half. At a ground incidence some power is scattered back along the direction of propagation, but most is reflected forward into a second hop, allowing, for instance, $1 \frac{1}{2} \mathrm{~F}$ ionospheric backscatter and $2 \mathrm{~F}$ 
ground backscatter to be observed at further ranges. More comprehensive nomenclature has been introduced (Davies, 1967) to describe some regions of backscatter, for instance the F-E/mode; in this system the $1 \frac{1}{2} \mathrm{~F}$ mode is termed the F-F/mode. (Note that in summer months the $\mathrm{F}$ region can separate into the $\mathrm{F} 1$ and $\mathrm{F} 2$ layers, allowing propagation by, for example, the $1 \mathrm{~F} 1$ and $1 \mathrm{~F} 2$ modes.) Three example rays are illustrated in Fig. 1, and it is possible that all three or a combination of them, can propagate simultaneously depending on the ionospheric electron density profile. The ranges indicated are also dependent on the ambient ionospheric conditions. Ray $A$ has a low elevation angle and backscatters and reflects in the E region; multiple hops are also possible here. Ray $B$ has a higher elevation angle and reflects in the $\mathrm{F}$ region, producing backscatter in both the $\mathrm{E}$ and $\mathrm{F}$ regions. Ray $C$ has the highest elevation angle and ionospheric refraction is insufficient to produce reflection, so the ray penetrates the ionosphere. In this case, though ionospheric backscatter can be observed in the $\mathrm{E}$ and $\mathrm{F}$ regions $\left(\frac{1}{2} \mathrm{E}\right.$ and $\frac{1}{2} \mathrm{~F}$ modes), no ground backscatter $(1 \mathrm{~F}$ or $2 \mathrm{~F})$ or far range ionospheric backscatter $\left(1 \frac{1}{2} \mathrm{~F}\right)$ is produced. The refraction effects in the ionosphere lead to a much larger viewing area at HF than can be achieved with VHF auroral radars, for which only the $\frac{1}{2} \mathrm{E}$ mode is possible.

Analysis of the auto-correlation function of the returned signals yields backscatter Doppler spectra, from which can be derived the spectral characteristics of power, line-of-sight Doppler velocity, $v_{\text {los }}$, and spectral width, $\Delta v$ (Hanuise et al., 1993). The Doppler velocity gives an estimate of the radar line-of-sight component of the plasma convection velocity (Nielsen and Schlegel, 1983; Villain et al., 1985; Ruohoniemi et al., 1987), and hence two radars with overlapping fields-of-view, such as CUTLASS, can create vector maps of convection flow across large regions of the high-latitude ionosphere (Nielsen et al., 1983b). For this reason SuperDARN radars are generally deployed in pairs, so as to give as wide a vector coverage of the auroral and polar cap region as possible.

Ionospheric backscatter spectra from the $\mathrm{E}$ region fall into two broad categories, type I and type II, depending on the instability mechanism of the ionospheric irregularity from which the radar has scattered (Fejer and Kelley, 1980; Fejer and Providakes, 1987). At $\mathrm{E}$ region altitudes the ion-neutral collision frequency is sufficiently high to constrain the ion population to the neutral flow speed, whereas the electrons move under the influence of the convection electric field with an $\mathbf{E} \times \mathbf{B}$ drift. This differential flow between ions and electrons gives rise to the two-stream (or Farley-Buneman) instability (Farley, 1963; Buneman, 1963), observed as type I Doppler spectra. Type I spectra have a low spectral width and a velocity constrained to be near the local ion-acoustic speed, $C_{\mathrm{s}}$, which typically takes a value of $350-400 \mathrm{~ms}^{-1}$ at $110 \mathrm{~km}$, the velocity threshold for the generation of the two-stream instability (Sudan, 1983; Nielsen and Schlegel, 1983). For high electron flow speeds, $C_{\mathrm{s}}$ (and hence the Doppler velocity of type I spectra) increases (Robinson, 1986), but in general remains an underestimate of the true drift speed. This is an important consideration for convection studies, producing inaccuracy not only in flow speed estimates, but also flow direction in the case of bistatic merged vector velocities; type I spectra are often considered to be contamination of HF radar backscatter.

A second plasma instability, the gradient-drift instability (Ossakow and Chaturvedi, 1979), exists at E region altitudes. The gradient-drift instability is generated in the presence of electron density gradients, and produces type II Doppler spectra in radar backscatter. There is no upper or lower velocity threshold for the generation of the gradient-drift instability, the irregularities produced moving with the background $\mathbf{E} \times \mathbf{B}$ drift. Hence, type II spectra give a true estimate of the convection flow speed. Type II spectra are generally broader than type I spectra. Secondary gradient-drift instabilities can also be generated within the modulated electron density of two-stream irregularities (Sudan et al., 1973; Haldoupis, 1988).

At $\mathrm{F}$ region altitudes, the ion-neutral collision frequency is low, so both ions and electrons move with the $\mathbf{E} \times \mathbf{B}$ drift and the two-stream instability is not generated. At these altitudes the gradient-drift instabil-

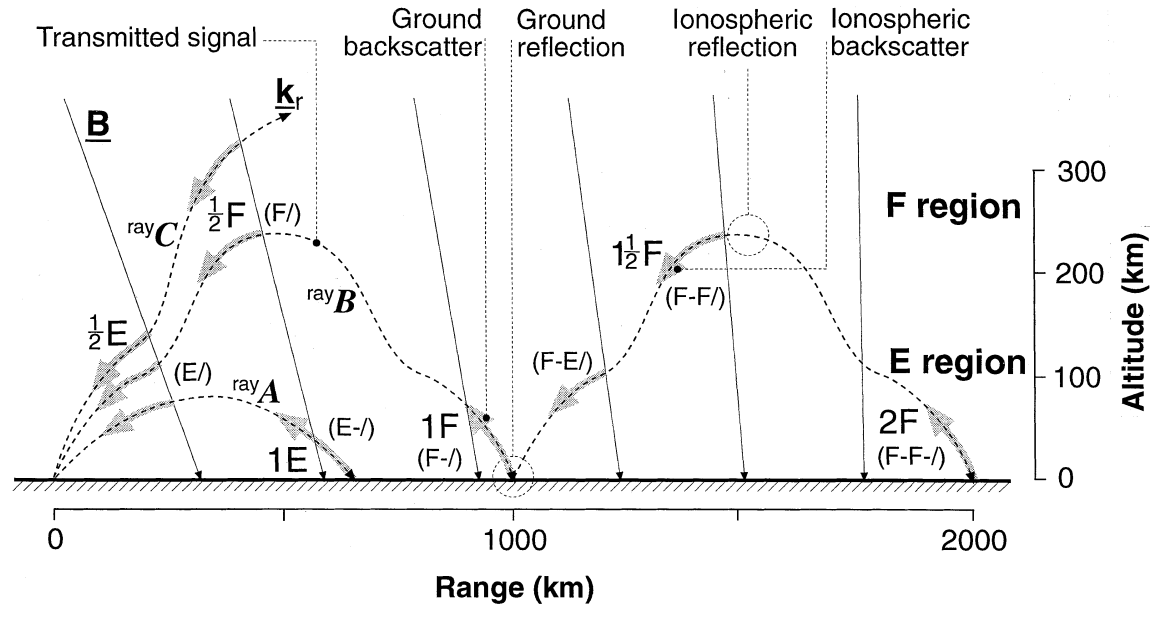

Fig. 1. A schematic diagram of some of the possible propagation modes and regions from which backscatter can occur. Mode nomenclature in parentheses follows Davies (1967). Ranges and altitudes are approximate and depend on ionospheric conditions. Three rays are illustrated: $A$ E region mode; $B \mathrm{~F}$ region mode producing far-range as well as nearrange backscatter; $C$ a ray that penetrates the ionosphere 
ity dominates, generated by electron density gradients at the edges of large $(\sim 10-100 \mathrm{~km})$ scale $F$ region irregularities (Tsunoda, 1988). Such large-scale features can be produced by structured soft precipitation in the auroral zones, both in the night sector and the dayside cusp, or structured convection in the presence of solar EUV ionisation gradients. These features have lifetimes of hours and can therefore be transported in the convection flow throughout the polar cap (Kelley et al., 1982).

Ground backscatter has near-zero velocity and low spectral width. The criteria typically applied for distinguishing ground backscatter from ionospheric backscatter are approximately $\left|v_{\text {los }}\right|<50 \mathrm{~m} \mathrm{~s}^{-1}$ and $\Delta v$ $<20 \mathrm{~m} \mathrm{~s}^{-1}$, although this can be ambiguous in some cases as such characteristics are not always inconsistent with ionospheric backscatter.

The propagation characteristics of HF radio waves, especially in the highly dynamic environment of the high-latitude ionosphere, are crucially important in determining the regions of the radar field-of-view that are illuminated and at which the orthogonality condition is satisfied. The diurnal variation of the occurrence of ground and ionospheric backscatter and the ranges from which such backscatter are returned display a significant seasonal variation. Investigation of this seasonal variation is crucial for understanding the propagation characteristics of the radar, for assessing the impact of these and other 'instrumental' effects on the geophysical interpretation of the data recorded, and for the planning of future campaign operations of the radar. The present study attempts to characterise the diurnal and seasonal variation of the coverage of the fields-of-view of the CUTLASS radars with ground and ionospheric backscatter, for the first 20 months and 12 months of operation of the Finland and Iceland radars respectively, and to discuss this in terms of the $\mathrm{HF}$ propagation conditions. The main section of the study, Sect. 4, concentrates on observations made at a radar operating frequency of $10 \mathrm{MHz}$, the most commonly employed frequency during the normal operation of the CUTLASS radars to date. The next section, 5, then briefly investigates the operating frequency dependence of backscatter occurrence. Finally, the effect of geomagnetic disturbance on the occurrence of backscatter is described in Sect. 6. Overall it is shown that the probability of observation of backscatter within a radar field-of-view is a convolution of the probability of occurrence of ionospheric irregularities within the fieldof-view and the ability of the radar to illuminate those regions of the field-of-view.

This study differs from previously presented statistical studies of SuperDARN radar data which have concentrated on purely geophysical interpretations of the observations. Previous studies include statistical convection patterns, binned according to IMF orientation, compiled for the Goose Bay radar (Ruohoniemi and Greenwald, 1995, 1996) and the Halley Bay radar (Leonard et al., 1995). Also, the Halley Bay radar has been employed to determine the seasonal dependence of the occurrence of polar cap patches (Rodger and Graham, 1996).

\section{The CUTLASS radars and the statistics data set}

The CUTLASS radars located at Hankasalmi $\left(62.3^{\circ} \mathrm{N}\right.$, $\left.26.6^{\circ} \mathrm{E}\right)$ in Finland and Pykkvibær $\left(63.8^{\circ} \mathrm{N}, 20.5^{\circ} \mathrm{W}\right)$ in Iceland (Fig. 2) have been operational since the end of February 1995 and mid-November 1995, respectively. The CUTLASS radars comprise two arrays of logperiodic antennas, a main array of 16 antennas, with both transmit and receive capability, and an interferometer array of 4 antennas with receive capability only. The radars can operate in the $\mathrm{HF}$ band between $8 \mathrm{MHz}$ and $20 \mathrm{MHz}$. The antennas in each array are phased with relationship to one another to form an antenna pattern in which the maximum gain (beam position) has one of 16 azimuthal pointing directions separated by approximately $3.2^{\circ}$, distributed symmetrically about the radar boresites of $-12^{\circ}$ (i.e. west of north) and $30^{\circ}$ (east of north) for the Finland and Iceland radars respectively. The fields-of-view of the CUTLASS radars include the European Incoherent Scatter radar (EISCAT) and the ionospheric heating facility at Tromsø, Norway, and the EISCAT Svalbard Radar (ESR) near Longyearbyen, Svalbard, both locations indicated in Fig. 2. The observation of backscatter from irregularities generated artificially by the Tromsø heater has confirmed the validity of the modelled Finland radar look-directions (Robinson et al., 1995).

In the normal scan mode of the radars, the 16 beams are sounded with a dwell time of $7 \mathrm{~s}$, producing field-ofview maps of backscatter, with an azimuthal coverage of over $50^{\circ}$, every 2 minutes. Typically, 75 range gates are sampled for each beam, with a pulse length of $300 \mu \mathrm{s}$, corresponding to a gate length of $45 \mathrm{~km}$, and a lag to the first gate of $1200 \mu \mathrm{s}(180 \mathrm{~km})$. In this configuration the maximum range of the radars is approximately $3550 \mathrm{~km}$, with each field-of-view containing 1200 cells.

A seven pulse scheme is transmitted, allowing the power and spectral width of the backscatter to be estimated by a functional fit to the decorrelation of the auto-correlation function at each range gate. Line-ofsight Doppler velocity is determined by a least squares fit to the phase of the complex value of the ACF as a function of lag. The elevation angle of backscatter can be determined from an interferometric analysis of the return backscatter, a phase difference being determined from the cross-correlation function of the signals received at the main and interferometer arrays.

For the present study a subset of the whole CUTLASS data set for the last 20 months was created, sixteen summary points being selected from the 1200 cells within each field-of-view. The aim of this study being to investigate the effect of HF propagation on the observation of backscatter, the variation of backscatter occurrence as a function of ground range was considered to be of greater interest than variation with azimuth, and hence the summary points were distributed along a single beam near the boresite of each radar, beam 9 in the case of the Finland radar and beam 7 in the case of the Iceland radar (illustrated in Fig. 2 and summarised in Table 1). The summary points span the AACGM coordinate system (based on Baker and Wing, 
1989) geomagnetic latitude range $65^{\circ} \mathrm{N}$ to $81^{\circ} \mathrm{N}$ in the case of the Finland radar, and $69^{\circ} \mathrm{N}$ and $73^{\circ} \mathrm{N}$ in the case of the Iceland radar. For each scan of the radars, backscatter parameters including power, velocity, noise and a flag indicating ground or ionospheric backscatter, are recorded for each summary point. The percentage of the total field-of-view which is filled with ionospheric and ground backscatter is also stored for each scan. The statistics data are taken from periods when the radars were running in the common time normal scan mode (50\% of operating time, see Greenwald et al., 1995) at approximately $10 \mathrm{MHz}$, the most commonly employed CUTLASS operating frequency over the phase of the solar cycle covered in the present study.

To aid the interpretation of the statistics data, Fig. 3 illustrates the diurnal variation in the locations of the sub-auroral, auroral and polar cap ionospheric regions with respect to the 16 summary points of each radar, for three levels of geomagnetic activity, quantified by the index $K_{\mathrm{p}}$. The auroral oval model employed is the statistical location of discrete optical emissions (Feldstein and Starkov, 1967; Holzworth and Meng, 1975).

\section{Ionospheric parameters as a function of season: the Tromsø dynasonde and Sodankylä ionosonde}

Before discussing the statistics of backscatter occurrence, the typical values of ionospheric critical frequencies within the radar's fields-of-view are presented. This
Table 1. The locations of the 16 summary points within the CUTLASs Finland and Iceland radar fields-of-view

\begin{tabular}{llrlllr}
\hline \multirow{2}{*}{$\begin{array}{l}\text { Summary } \\
\text { point }\end{array}$} & $\begin{array}{l}\text { Range } \\
\text { gate }\end{array}$ & $\begin{array}{l}\text { Range } \\
(\mathrm{km})\end{array}$ & \multicolumn{6}{l}{ Geographic coordinates } \\
\cline { 4 - 7 } & & & \multicolumn{5}{l}{ Finland radar } & \multicolumn{2}{l}{ Iceland radar } \\
\hline 0 & 13 & 720 & $69.1^{\circ} \mathrm{N}$ & $24.2^{\circ} \mathrm{E}$ & $69.6^{\circ} \mathrm{N}$ & $11.5^{\circ} \mathrm{W}$ \\
1 & 15 & 810 & $69.9^{\circ} \mathrm{N}$ & $23.8^{\circ} \mathrm{E}$ & $70.2^{\circ} \mathrm{N}$ & $9.7^{\circ} \mathrm{W}$ \\
2 & 18 & 945 & $71.1^{\circ} \mathrm{N}$ & $23.2^{\circ} \mathrm{E}$ & $71.2^{\circ} \mathrm{N}$ & $7.4^{\circ} \mathrm{W}$ \\
3 & 20 & 1035 & $71.9^{\circ} \mathrm{N}$ & $22.7^{\circ} \mathrm{E}$ & $71.8^{\circ} \mathrm{N}$ & $5.7^{\circ} \mathrm{W}$ \\
4 & 23 & 1170 & $73.1^{\circ} \mathrm{N}$ & $22.0^{\circ} \mathrm{E}$ & $72.7^{\circ} \mathrm{N}$ & $3.0^{\circ} \mathrm{W}$ \\
5 & 25 & 1260 & $73.9^{\circ} \mathrm{N}$ & $21.4^{\circ} \mathrm{E}$ & $73.2^{\circ} \mathrm{N}$ & $1.0^{\circ} \mathrm{W}$ \\
6 & 27 & 1350 & $74.7^{\circ} \mathrm{N}$ & $20.7^{\circ} \mathrm{E}$ & $73.8^{\circ} \mathrm{N}$ & $1.1^{\circ} \mathrm{E}$ \\
7 & 30 & 1485 & $75.9^{\circ} \mathrm{N}$ & $19.7^{\circ} \mathrm{E}$ & $74.5^{\circ} \mathrm{N}$ & $4.6^{\circ} \mathrm{E}$ \\
8 & 32 & 1575 & $76.7^{\circ} \mathrm{N}$ & $18.8^{\circ} \mathrm{E}$ & $75.0^{\circ} \mathrm{N}$ & $7.0^{\circ} \mathrm{E}$ \\
9 & 35 & 1710 & $77.8^{\circ} \mathrm{N}$ & $17.4^{\circ} \mathrm{E}$ & $75.7^{\circ} \mathrm{N}$ & $11.0^{\circ} \mathrm{E}$ \\
10 & 37 & 1800 & $78.6^{\circ} \mathrm{N}$ & $16.3^{\circ} \mathrm{E}$ & $76.1^{\circ} \mathrm{N}$ & $13.9^{\circ} \mathrm{E}$ \\
11 & 40 & 1935 & $79.8^{\circ} \mathrm{N}$ & $14.3^{\circ} \mathrm{E}$ & $76.7^{\circ} \mathrm{N}$ & $18.5^{\circ} \mathrm{E}$ \\
12 & 43 & 2070 & $80.9^{\circ} \mathrm{N}$ & $11.8^{\circ} \mathrm{E}$ & $77.1^{\circ} \mathrm{N}$ & $23.4^{\circ} \mathrm{E}$ \\
13 & 46 & 2205 & $82.0^{\circ} \mathrm{N}$ & $8.6^{\circ} \mathrm{E}$ & $77.5^{\circ} \mathrm{N}$ & $28.7^{\circ} \mathrm{E}$ \\
14 & 49 & 2340 & $83.1^{\circ} \mathrm{N}$ & $4.3^{\circ} \mathrm{E}$ & $77.7^{\circ} \mathrm{N}$ & $34.2^{\circ} \mathrm{E}$ \\
15 & 52 & 2475 & $84.2^{\circ} \mathrm{N}$ & $1.4^{\circ} \mathrm{W}$ & $77.9^{\circ} \mathrm{N}$ & $40.0^{\circ} \mathrm{E}$ \\
\hline
\end{tabular}

will allow determination of propagation conditions and illustrates the large variation in the ambient ionospheric environment in which the radars operate during different times of year.

Ionograms from the dynasonde located at the EISCAT facility in Tromsø, Norway (approximately collocated with beam 5, range gate 17 of the Finland radar field-of-view), provide the diurnal variation of the ionospheric electron density profile at the solstices and

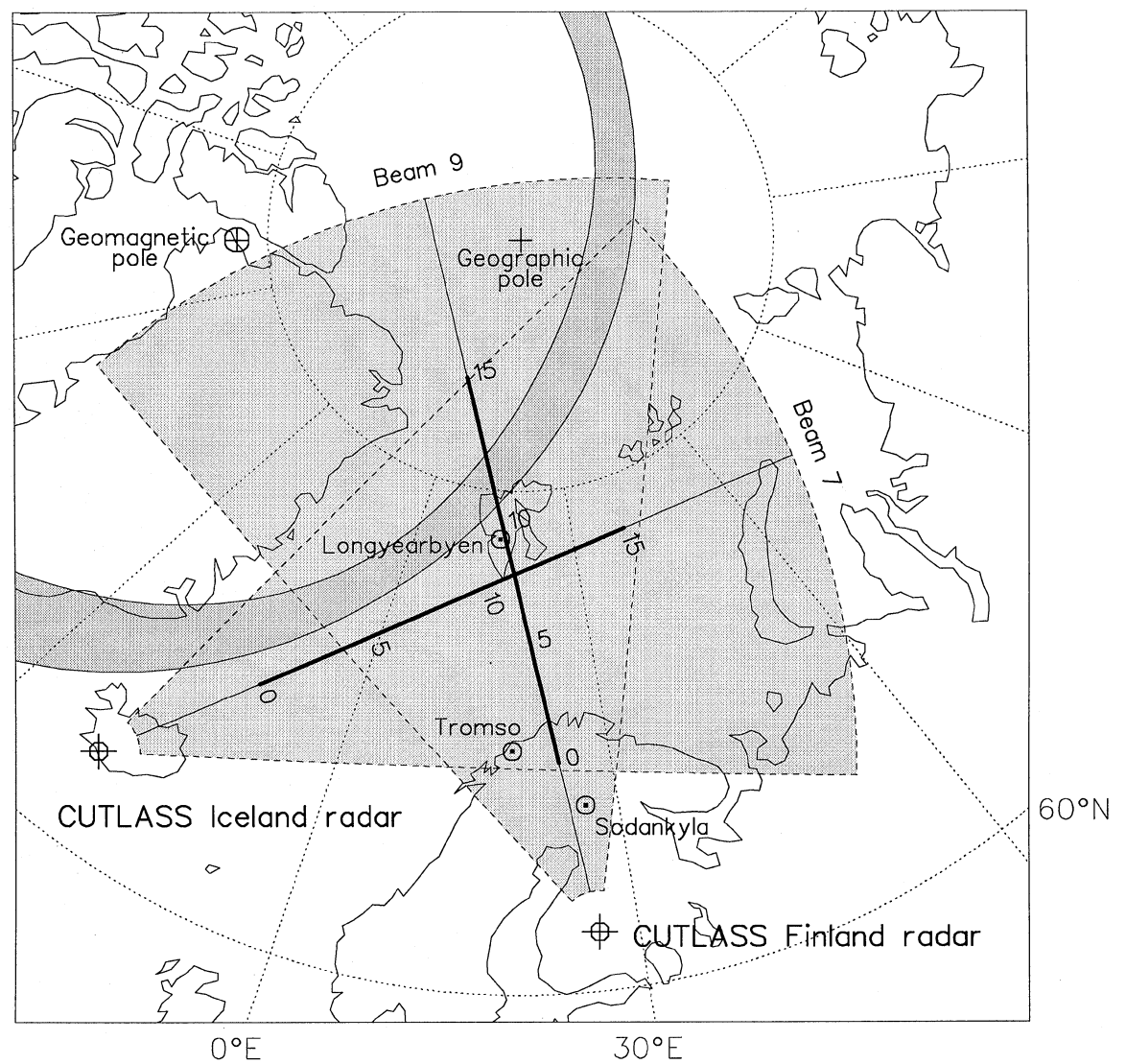

Fig. 2. The location of the summary points within the fields-of-view of the cutLass Finland and Iceland radars. Thin lines indicate the summary beams ( 9 and 7 for the Finland and Iceland radars respectively), the thick lines indicating the range interval over which summary data is collected. Numbers to the right of the thick lines indicate the numbering of the summary points. The locations of Tromsø, Norway, Sodankylä, Finland, and Longyearbyen, Svalbard, are also indicated, along with the statistical location of the quiet $\left(K_{\mathrm{p}}=0\right)$ auroral oval at 06 uT (Feldstein and Starkov, 1967; Holzworth and Meng, 1975). 


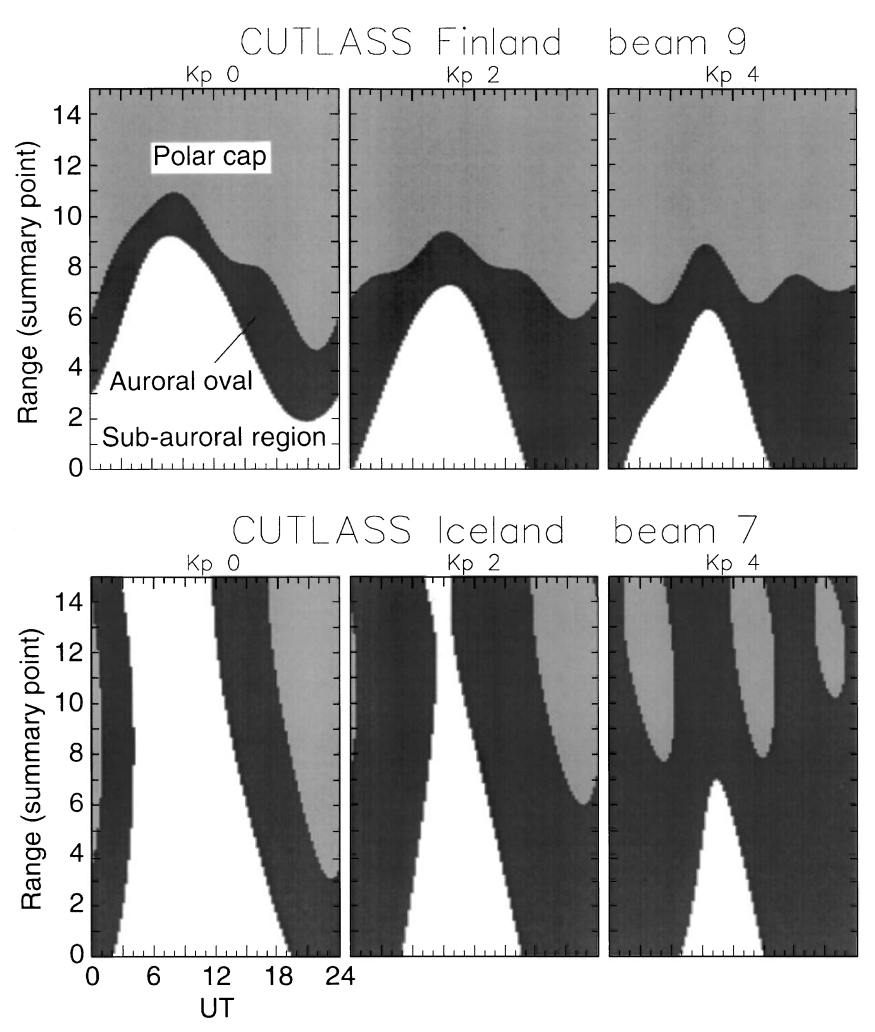

Fig. 3a, b. The diurnal variation in the statistical location of the subauroral, auroral, and polar cap ionospheric regions along the summary beams of the CUTLASS radars, for different levels of geomagnetic activity

equinoxes. Days were selected from 1995 as close to the solstices and equinoxes as possible, for which dynasonde data were available and which the CUTLASS data suggested were undisturbed (i.e. non-storm). These days were 8 June and 21 December 1995 for the summer and winter solstices and 21 March and 22/23 September 1995 for the spring and autumn equinoxes. In the first three cases, 24 hours of data from 00 UT to 24 UT were analysed. For the autumn equinox, only 21 hours of data were available, from 15 UT 22 September to 11 UT 23 September 1995. These intervals had values of $K_{\mathrm{p}}$ ranging from 0 to $3+$, none having $\Sigma K_{\mathrm{p}}$ greater than 12 .

The parameters scaled from the ionograms included the critical frequencies of the $\mathrm{E}$ region, $f_{0} E$, the auroral precipitation-enhanced $\mathrm{E}$ region, $f_{0} E_{\mathrm{s}}$, and the $\mathrm{F} 1$ and F2 regions, $f_{0} F 1$ and $f_{0} F 2$. The layer heights measured were: $h F 1$, the lowest height of the F1 trace; $h F 2$, the lowest height of the $\mathrm{F} 2$ trace and $h_{\mathrm{m}} F 2$, the maximum height observed in the F2 trace (see schematic in Fig. 4 which is representative of a daytime summer or equinox ionogram). All heights are virtual. The $\mathrm{E}$ region height, $h E$, was not tabulated as the E region remained at an approximately constant altitude of $110 \mathrm{~km}$. The diurnal variations of these parameters are illustrated in Fig. 5. The variations from both equinoxes are similar, but very different from the solstices. The $\mathrm{E}$ and $\mathrm{F} 1$ regions are observed during the summer solstice and both equinoxes, but are absent in winter, except for a sporadic E region. At the summer solstice the ionosphere above

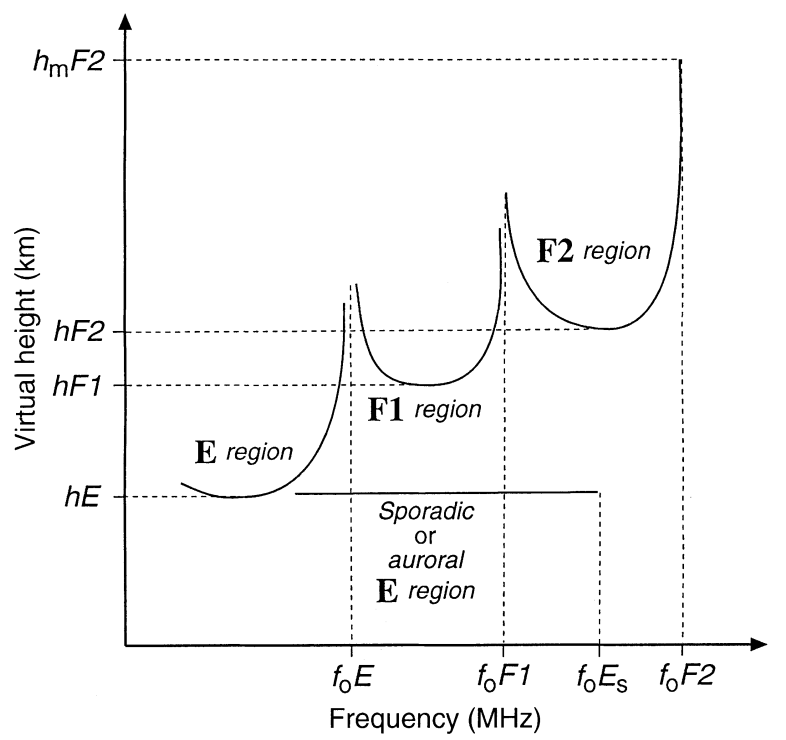

Fig. 4. A schematic representation of a summer or equinox daytime ionogram, indicating the parameters scaled from the Tromsø dynasonde data

Tromsø is illuminated at all times and $f_{0} F 2$ remains constant at approximately $5 \mathrm{MHz}$ throughout the day. The daytime maximum in $f_{0} F 2$ is approximately $5 \mathrm{MHz}$ at both the equinoxes, but $f_{0} F 2$ decreases at night to $2 \mathrm{MHz}$. At the winter solstice the $\mathrm{F}$ region is only weakly formed near noon, with $f_{0} F 2$ approximately $3 \mathrm{MHz}$, and cannot be detected by the dynasonde at night.

Monthly median diurnal variations of $f_{0} E, f_{0} F 1$ and $f_{0} F 2$ were also available from Sodankylä, Finland, for each month of 1990, near solar maximum, and 1995, the period of the present study and near solar minimum, presented in Fig. 6. The absence of an $f_{0} E$ trace near midday during summer months is a consequence of radio wave attenuation in the $\mathrm{D}$ region. The major difference to note between solar cycle phases is that $f_{0} F 1$ and $f_{0} F 2$ are generally higher at solar maximum that at solar minimum, by a factor of approximately 2 in winter and 1.5 in summer.

\section{Ground and ionospheric backscatter occurrence within the fields-of-view of the CUTLASS radars at $10 \mathrm{MHz}$}

To illustrate the backscatter occurrence, the top panels of Fig. 7a, b indicate the mean diurnal variation in the coverage of the whole field-of-view of the Finland and Iceland radars respectively with ground (ionospheric) backscatter, represented by the blue (red) line. The bottom two sets of panels represent the summary point occupancy, the monthly mean percentage of scans in each two hour interval which contain either ground or ionospheric backscatter for each of the 16 summary points in the statistics data base. It must be borne in mind during the following discussion that these data have been compiled for a radar operating frequency of $10 \mathrm{MHz}$ only. 


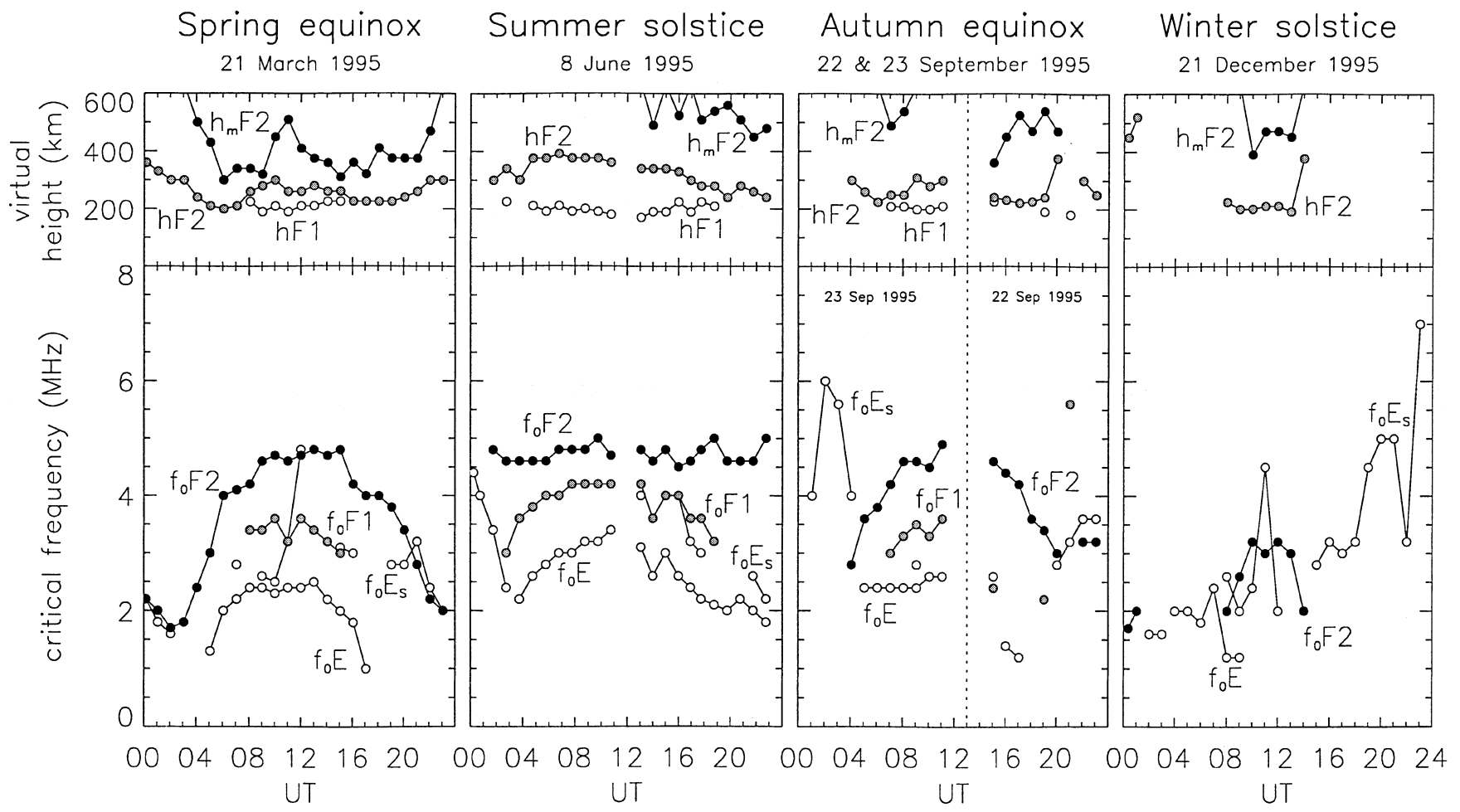

Fig. 5. Ionospheric parameters measured by the Tromsø dynasonde for four days near the solstices and equinoxes of 1995

\subsection{Ground backscatter}

The following discussion of ground backscatter occurrence concentrates on the Finland radar observations (Fig. 7a), due to its longer period of operation; the ground backscatter observations of the Iceland radar (Fig. 7b) are essentially very similar. The period of the day during which ground scatter is present displays a seasonal variation, due to the variation in the illumination and hence ionisation of the $\mathrm{E}$ and $\mathrm{F}$ regions. During summer months, especially June and July 1995, ground backscatter is present almost throughout the day as $f_{0} F 2 \approx 5 \mathrm{MHz}$ at all times (see Sect. 3), and ionospheric refraction is sufficient to reflect the $10 \mathrm{MHz}$ radar signal back to the ground. During the equinoctial months March and September 1995, ground backscatter is observed predominantly between 04 UT and 18 UT, as at other times the $\mathrm{F}$ region electron density is low, $f_{0} F 2 \approx 2 \mathrm{MHz}$ (see Sect. 3), and the radar signal penetrates the ionosphere. In winter months ground backscatter is observed for a shorter period, between 06 UT and 14 UT during December 1995. The ground scatter traces display a U-shaped variation in range, symmetrical about local noon. This is a consequence of the variation in skip distance, the nearest range to which ionospheric refraction is sufficient to reflect the radar ray back to the ground, with the variation in the ionospheric electron density, specifically that of the $\mathrm{F} 1$ region in summer months and the $\mathrm{F} 2$ region in other months. As the ionospheric electron density increases near local noon, the skip distance decreases.
A previous study of the interferometer results of the CUTLASS radars (Milan et al., 1997) indicated that a significant proportion of ground backscatter originates behind (i.e. equatorward of) the radars as a consequence of a rear lobe in the antenna patterns and favourable propagation conditions at mid latitudes. Interferometer information can distinguish between front and rear backscatter as backscatter from in front of the radars has elevation angles which tend to decrease with increasing range (consistent with HF propagation characteristics) and backscatter from behind the radars has elevation angles which increase with range (due to $2 \pi$ ambiguities in determining the phase delay, Milan et al., 1997). Thus, comparing elevation angle occurrence distributions from different ranges it is possible to identify two populations of observations, which increase and decrease in elevation angle with increasing range. This gives a (very approximate) estimate of the proportion of ground backscatter observed by the radars which originates in the front and rear fields-of-view, illustrated in Fig. 8, for the months November 1995 to October 1996, the period during which the interferometers have been operational. A minimum occurs in December 1995, when only $10 \%$ to $15 \%$ of ground backscatter originates in front of the radars. By April to May and August to September 1996 this value has risen to between $60 \%$ and $75 \%$. In mid-summer the proportion of backscatter from the front field-of-view decreases to $60 \%$ and $40 \%$ in the case of the Finland and Iceland radars respectively. In winter, the polar cap ionosphere is poorly illuminated and $f_{0} F 2$ is extremely low except between 10 UT and 13 UT (see Sect. 3) and even during this period 

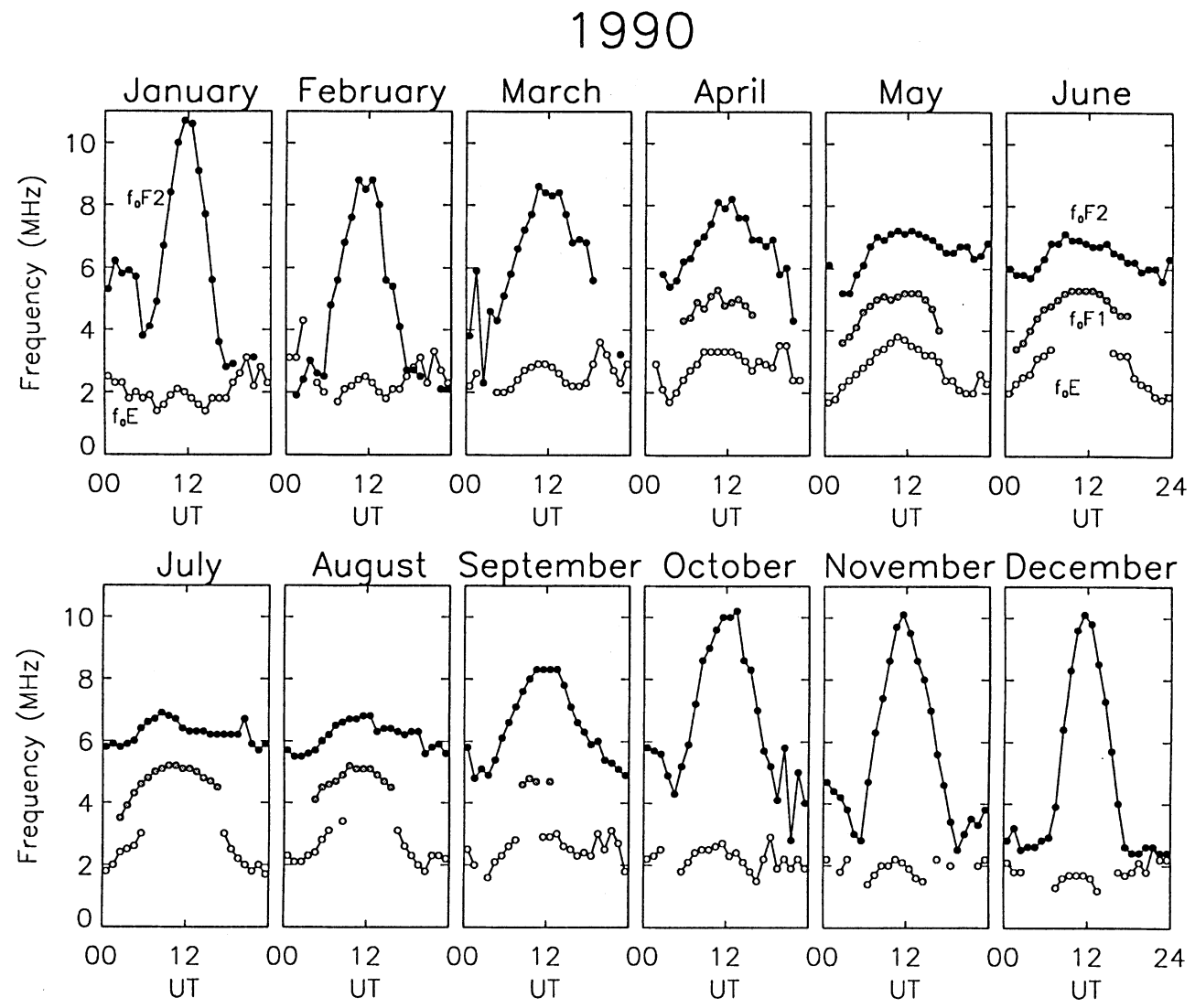

1995
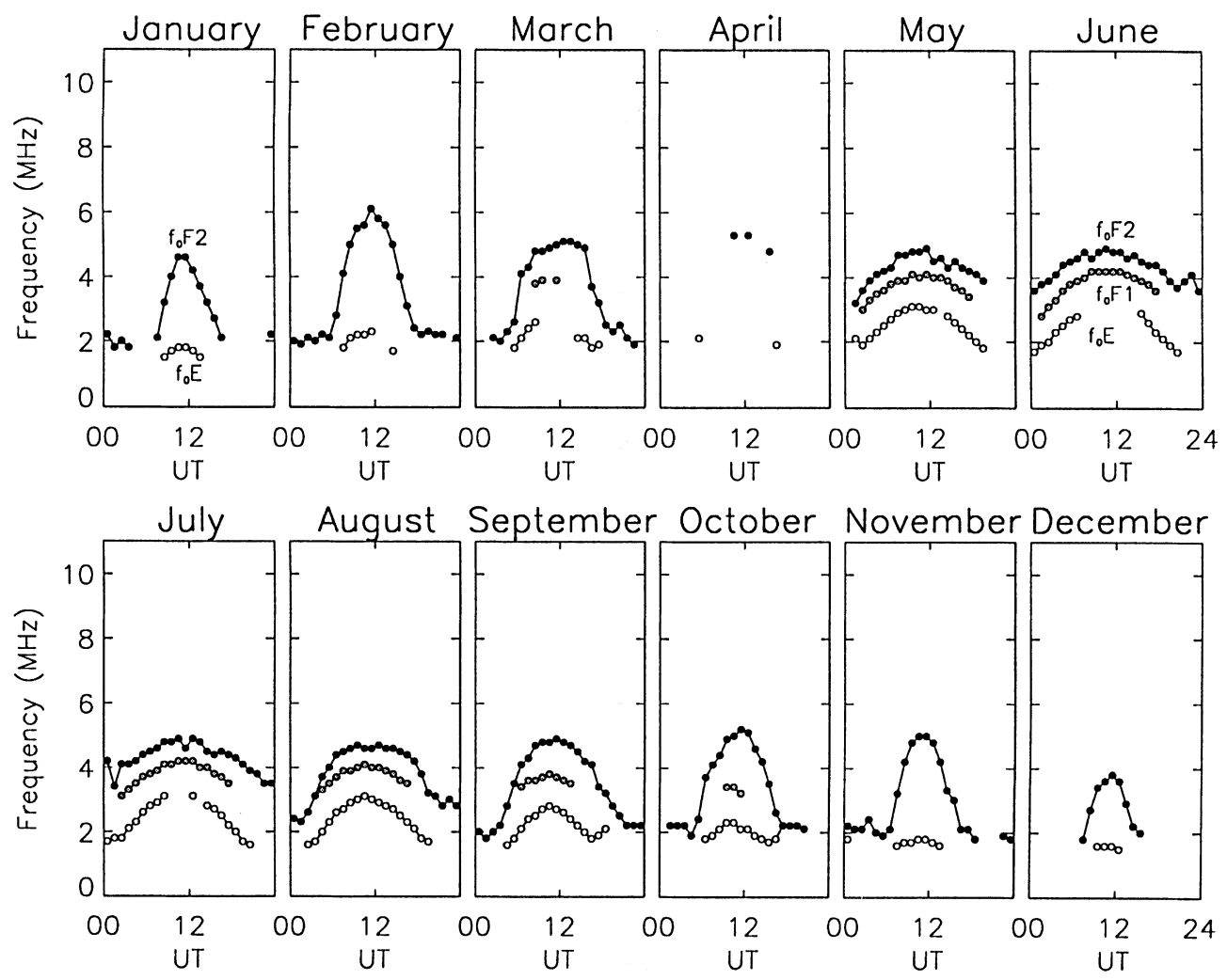

Fig. 6. Monthly median values of ionospheric parameters from the Sodankylä ionosonde for near solar maximum conditions (1990) and near solar minimum conditions (1995) 
CUTLASS Finland
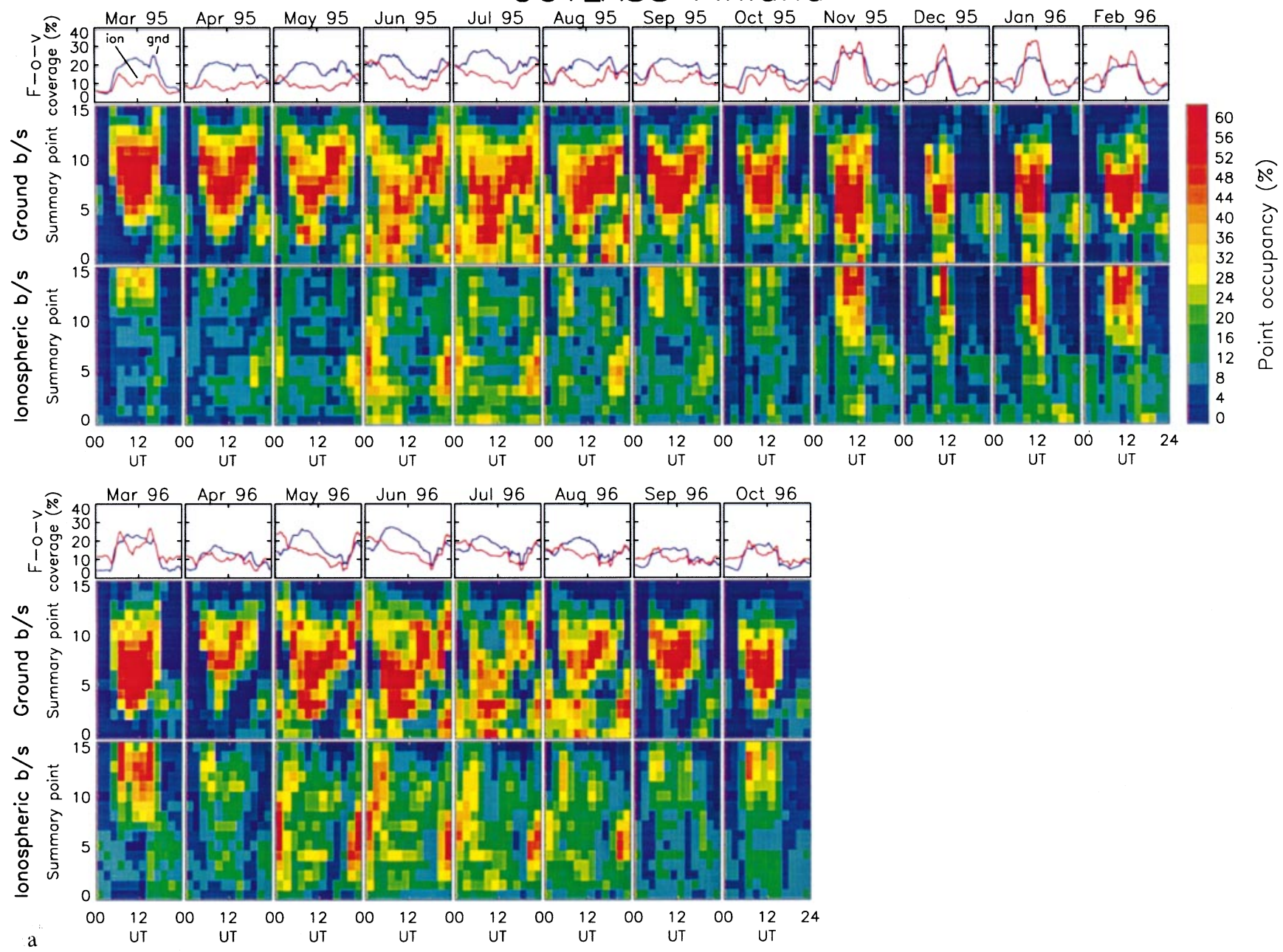

CUTLASS Iceland

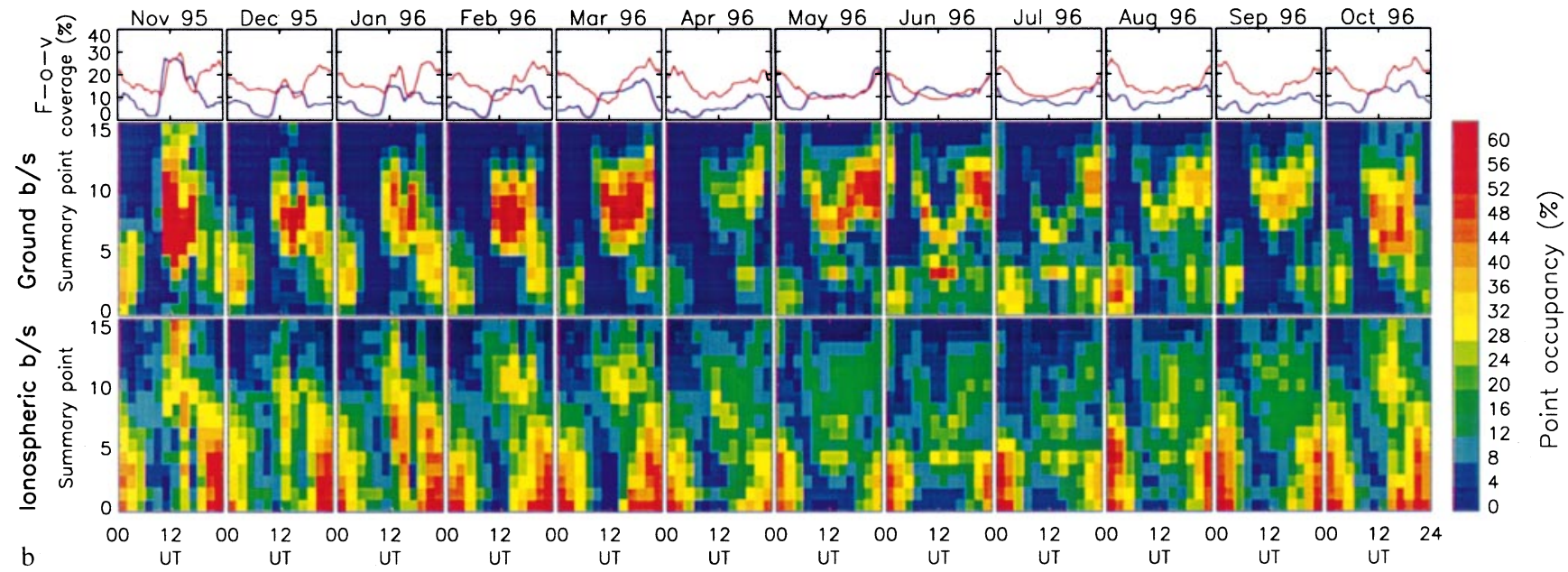

Fig. 7a. Finland radar top panels the diurnal variation in the percentage field-of-view coverage of ionospheric and ground backscatter for the months March 1995 to June 1996. Middle and bottom panels, the point occupancy as a function of range (summary point) for

propagation polewards of the radars is easily disrupted by ionospheric disturbances. Equatorwards of the radars, at mid latitudes, the winter day is longer and ground and ionospheric backscatter for the months March 1995 to June 1996. b Iceland radar. Similar to a, though for months November 1995 to June 1996

$f_{0} F 2$ much higher (up to $10 \mathrm{MHz}$ and more due to the seasonal anomaly, Davies, 1990) and consequently most ground backscatter is observed from this region. In 


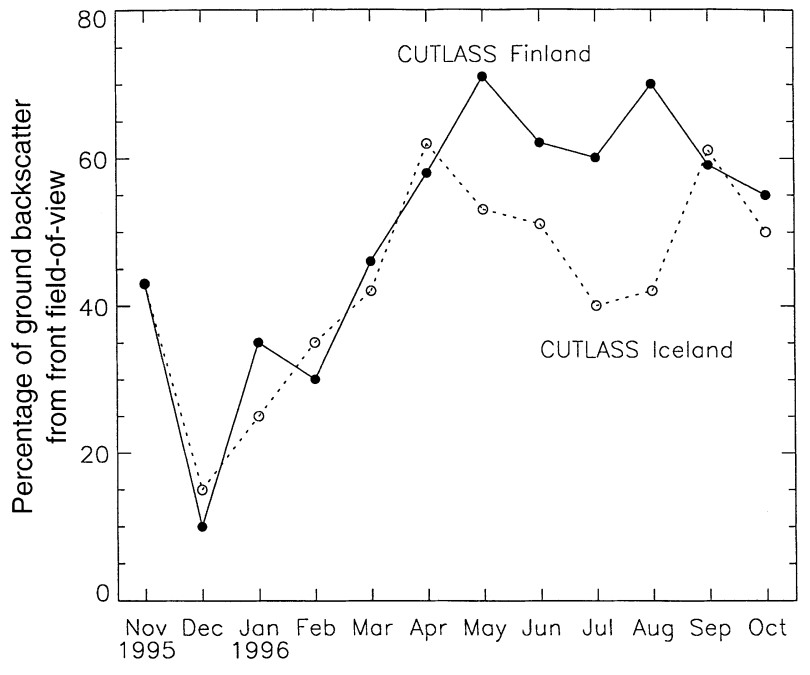

Fig. 8. The monthly variation in the percentage of ground backscatter originating in the front fields-of-view of the cUTLASS radars

summer the polar cap ionosphere is well illuminated for large portions of the day and consequently the proportion of ground scatter originating at these latitudes is much higher. In mid-summer, however, the proportion of backscatter originating in the front field-of-view begins to fall again as a nighttime propagation mode to the south of the radars becomes increasingly important. Backscatter propagating by this mode is visible as a Ushaped region of ground backscatter between 16 UT and 00 UT, for instance May, June and July 1996 in the case of the Finland radar (Fig. 7a). In the rest of this discussion, only ground backscatter originating in the front field-of-view is considered.

Throughout the summer solstice and spring and autumn equinox periods (e.g. March to September 1995) most ground scatter at ranges of $1200 \mathrm{~km}$ (summary point 5) and beyond is supported by the 1F2 mode, though the 1F1 mode increases in importance near the summer solstice (see Sect. 3). The 1F1 and 1F2 modes are distinguishable with elevation angle information. During summer months, daytime ground backscatter appears at nearer ranges, for instance around $1000 \mathrm{~km}$ (summary points 2 and 3) in May and August 1995 and $720 \mathrm{~km}$ to $1200 \mathrm{~km}$ (summary points 0 to 4 ) during June and July 1995. This ground scatter is a consequence of propagation via the $\mathrm{E}$ region as daytime values of $f_{0} E$ reach $3 \mathrm{MHz}$ at noon. In both June and July the ranges covered by $\mathrm{E}$ and $\mathrm{F}$ region ground backscatter overlap near summary points 4 and 5. During winter months, the elevation angle distribution is consistent with propagation by a single $F$ region reflecting layer only, in agreement with the ionogram data (see Sect. 3).

Ground backscatter is also observed at near ranges, summary points 0 to $4\left(66\right.$ to $\left.70^{\circ} \mathrm{N}\right)$, during the midnight sector ( 22 to 02 UT) during the summer months May to August. This ground backscatter propagates via auroral $E$ layers. The seasonal dependence of the occurrence of this auroral E propagation is attributed to the presence of a solar produced $\mathrm{E}$ region at all times of day during summer months. Although $f_{0} E$ falls to below $2 \mathrm{MHz}$ at
$00 \mathrm{UT}$, insufficient to support the $10 \mathrm{MHz}$ radar signal, only a small flux of auroral precipitation is necessary to enhance $f_{0} E$ to $f_{0} E_{\mathrm{s}}$ values capable of producing reflection. During winter months, $f_{0} E$ is extremely low at 00 UT, and consequently much higher auroral precipitation fluxes are necessary to give rise to E region propagation.

The Iceland observations follow the same trends as the Finland observations, though occurrence tends to be lower in Iceland, especially during the period April to September 1996. Very low occurrences of daytime ground backscatter observed by both radars in April and July 1996 are a consequence of the geomagnetically disturbed nature of the relatively few days during which data were collected in those months. The geomagnetic activity dependence of the observations will be discussed more fully in Sect. 6.

The similarity of the Finland and Iceland ground backscatter observations indicates that the propagation conditions are alike for both radars, despite the Finland and Iceland summary beams being aligned essentially north-south and east-west respectively.

\subsection{Ionospheric backscatter}

Ionospheric backscatter occurrence is different for the Finland and Iceland radars. As indicated in Sect. 4.1, the ionospheric propagation conditions for both radars are similar, suggesting that any ionospheric backscatter occurrence difference has a geophysical basis as opposed to depending on propagation characteristics alone. The observations of the Finland radar will be discussed first (Fig. 7a).

The time of day and range at which ionospheric backscatter regularly appears displays a seasonal dependence. In months March 1995, November 1995 to March 1996, and October 1996 most ionospheric backscatter is observed at far ranges (approximately summary point 10 and beyond, geomagnetic latitudes above $75^{\circ} \mathrm{N}$ ) between $06 \mathrm{UT}$ and $16 \mathrm{UT}$. For the following discussion these months will be referred to as winter months. During months June to August 1995 and May to August 1996, most ionospheric backscatter is observed at near ranges (between summary points 3 and 9) between 20 UT and 02 UT. These months will be referred to as summer months. Between these summer and winter intervals, during the months April to May and October 1995, April and September 1996, near the spring and autumn equinoxes, relatively little ionospheric backscatter is observed.

During winter months, when ionospheric backscatter occurs at ranges 10 and beyond, the period of the day when backscatter appears (06 UT to 16 UT in March 1995, 10 UT to 12 UT during December 1995) mirrors the period during which ground backscatter, originating from in front of the radar and propagating by the $1 \mathrm{~F}$ mode from ranges between summary points 5 and 9 , is observed. As ionospheric backscatter from such ranges $(\approx 2300 \mathrm{~km})$ must be multi-hop due to the curvature of the Earth, the propagation mode appears to be the $1 \frac{1}{2} \mathrm{~F}$ 
mode, confirmed by elevation angle information. The $1 \frac{1}{2} \mathrm{~F}$ mode can only propagate when the $1 \mathrm{~F}$ mode propagates, and thus can not appear during the winter night as $f_{0} F 2$ is too low to support the ionospheric reflection of the $10 \mathrm{MHz}$ radar beam (see Sects. 1 and 4.1).

The diurnal variation of the occurrence of far range ionospheric backscatter generally exhibits two maxima, one pre-noon and a second post-noon (see especially the months March 1995, September 1995 to March 1996, and September to October 1996, top panels Fig. 7a). The times of these maxima vary with month (see Fig. 9), in general being most separated near the equinoxes and approaching local noon towards winter solstice, until they merge to form a single peak in December 1995 and January 1996. A comparison of the Sodankylä ionosonde measurements with the times of the maxima in backscatter occurrence (shifted by $1 \mathrm{~h}$ to account for differences in longitude) indicates that the peaks in the occurrence of backscatter occur when $f_{0} F 2$ at Sodankylä is approximately $4 \mathrm{MHz}$. Values of $f_{0} F 2$ above $4 \mathrm{MHz}$ lead to a decrease in the occurrence of $F$ region backscatter observation. An initial ray-tracing analysis suggests that increasing values of $f_{0} F 2$ produce a decrease in the reflection height of the radar signal, screening higher altitudes of the $\mathrm{F}$ region where irregularities predominate. This indicates that an optimum operating frequency exists for a particular value of $f_{0} F 2$ which maximises the probability of observing far range $\mathrm{F}$ region backscatter. This suggests the possibility of a

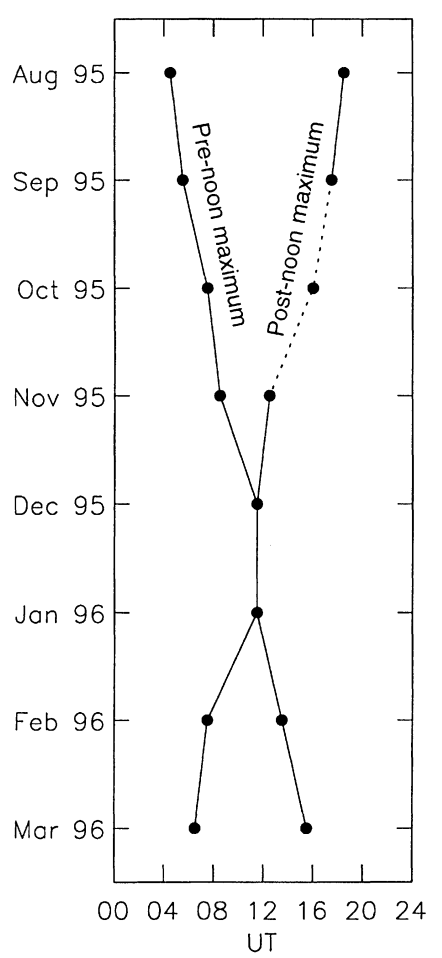

Fig. 9. The monthly variation in the times of maxima in the occurrence of ionospheric backscatter observed with the Finland radar. The post-noon maximum for October 1995 is very broad and hence the centre is marked frequency management scheme for the radars, which will be discussed in Sect. 5 .

Little daytime ionospheric backscatter appears in winter months at ranges closer than summary point 10 (geomagnetic latitudes below $75^{\circ} \mathrm{N}$ ), i.e. propagating by the $\frac{1}{2} \mathrm{~F}$ mode. It would be expected that the radar would illuminate this region of the ionosphere. As indicated by Fig. 3a (see Sect. 2), near local noon the auroral oval is located at latitudes poleward of the radar and ranges closer than summary point 10 are within the sub-auroral ionosphere where ionospheric irregularities capable of scattering the radar signals are generally not present (except under intense sporadic E conditions e.g. Haldoupis and Schlegel, 1993; Haldoupis et al., 1996). In this case the absence of scatter is a geophysical not instrumental effect.

In summer months no $1 \frac{1}{2} \mathrm{~F}$ mode ionospheric backscatter is observed, despite the $\mathrm{F}$ region electron density being sufficiently high to support $\mathrm{F}$ region propagation throughout most of the day. This can be considered as a continuation of the trend observed in winter months when values of $f_{0} F 2$ above $4 \mathrm{MHz}$ near local noon lead to a decrease in far range backscatter occurrence (see earlier). During summer months $f_{0} F 2>4 \mathrm{MHz}$ at all times and a well-formed $\mathrm{F} 1$ region also exists. In this case it might be expected that increasing the radar operating frequency would increase the occurrence of backscatter (see Sect. 5). There are also possible geophysical reasons for the absence of backscatter, as constant solar illumination during summer months produces a homogenous polar cap ionosphere in which electron density gradients are low (Bowline et al., 1996), constraining irregularity formation by the gradient-drift instability. Rodger and Graham (1996) interpret the decrease in far-range backscatter observed by the BAS Halley Bay HF radar during (southern hemispheric) summer months as a decrease in the occurrence of polar cap patches convecting anti-sunward within the convection pattern (Weber et al., 1984; Carlson, 1994). Such an interpretation would also require that the cusp region in summer does not generate irregularities from which HF radars can scatter.

It is during this period, June to August 1995 and May to August 1996, however, that ionospheric backscatter is observed at near ranges (summary points 3 to 9 ) between 20 UT and 02 UT, when the auroral oval has moved to the near-range field-of-view of the radar (see Fig. 3). This backscatter has elevation angles consistent with $\mathrm{F}$ region backscatter, propagating by the $\frac{1}{2} \mathrm{~F}$ mode, as at this time of year $f_{0} F 2$ is sufficiently high in this local time sector that ray refraction can bring the radar wave vector orthogonal with the geomagnetic field. This is probably not possible at the nearest ranges (summary points 0 to 2 ), however, due to the steepness of the take-off angle required. At this time of year auroral $\mathrm{E}$ ground backscatter is also observed at near ranges (see Sect. 4.1).

The most obvious difference in the Iceland observations is the greater quantity of near-range ionospheric backscatter seen by this radar. This scatter is predominantly $\mathrm{E}$ region scatter, generated by the two-stream instability. The threshold condition for the growth of 
this instability, such that it can be observed by the radar, is that the line-of-sight plasma velocity exceeds the local ion-acoustic velocity, $C_{\mathrm{s}}$ (see Sect. 1). As the convection flow at auroral latitudes is predominantly zonal, higher plasma velocities are necessary to meet the $v_{\text {los }}>C_{\mathrm{s}}$ threshold within the Finland radar field-of-view, which in general has a large flow angle (the angle between the radar beam and direction of flow), than in the Iceland radar field-of-view which has a larger boresite azimuth and hence lower flow angle. Between summary points 0 and 10 , the geomagnetic azimuth variation is $14^{\circ}$ to $17^{\circ}$ for the Finland radar (flow angles above $70^{\circ}$ ), and $50^{\circ}$ to $60^{\circ}$ in the case of the Iceland radar (flow angles as low as $30^{\circ}$ ). For this reason more $\mathrm{E}$ region ionospheric backscatter is observed by the Iceland radar than the Finland radar, and such backscatter is observed at even the nearest ranges (summary points 0 to 2 ) where the orthogonality condition is easily met at $\mathrm{E}$ region altitudes.

The other major difference between the Iceland and Finland observations is the occurrence of local midday ionospheric backscatter at near ranges (summary points 2 to 9), with elevation angles consistent with the $\frac{1}{2} \mathrm{~F}$ mode, in addition to scatter from far ranges (summary points 10 to 15 ) propagating by the $1 \frac{1}{2} \mathrm{~F}$ mode, during the months November 1995 to January 1996. Backscatter can be observed at these ranges as a consequence of the oblique orientation of the Iceland radar field-of-view with respect to the auroral oval. As illustrated in Fig. 3b, at low $K_{\mathrm{p}}$ values the auroral oval is confined to latitudes polewards of the summary beam between 04 UT and 12 UT, and for this reason little ionospheric backscatter is observed during this interval as the subauroral ionosphere has a low occurrence of ionospheric irregularities. However, from 12 UT onwards and at higher $K_{\mathrm{p}}$ values, the auroral oval moves to lower latitudes, across the beam, so that by 18 UT the statistics beam is within the auroral oval or the polar cap ionosphere (where irregularities are also present) at all ranges. Little $\mathrm{F}$ region ionospheric backscatter is observed after $16 \mathrm{UT}$ as at this time $f_{0} F 2$ decreases and propagation is no longer supported. From April to September 1996, the occurrence of local midday ionospheric backscatter decreases, as in the case of the Finland radar, again illustrating that propagation conditions are not suitable for the observation of $F$ region ionospheric backscatter during summer months at a frequency of $10 \mathrm{MHz}$; the effect of increasing the radar operating frequency is discussed in Sect. 5.

Finally, an examination of the spectral moments of the Iceland observations provides evidence that $\mathrm{E}$ region as well as $\mathrm{F}$ region ionospheric backscatter can be observed at far ranges (ranges beyond summary point 12) during winter months. A scatter plot of spectral width against velocity for far-range backscatter during January 1996 (Fig. 10) indicates a population of points with $v_{\text {los }} \approx C_{s}$ and $\Delta v \lesssim 200$ VHF s ${ }^{-1}$, which are characteristics of type I Doppler spectra which originate in the $\mathrm{E}$ region (see Sect. 1). The type I population is superimposed on a broader velocity and width population, originating in the $\mathrm{F}$ region. The cluster of points

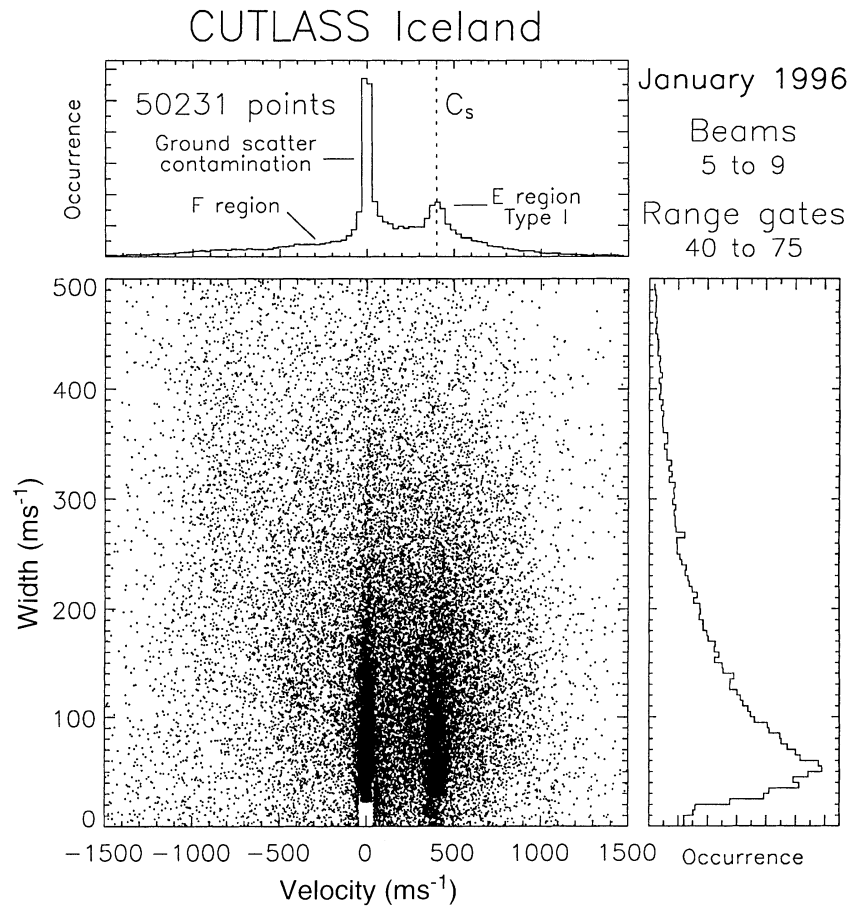

Fig. 10. A scatter plot of spectral width against Doppler velocity of backscatter observed in beams 5 to 9 , range gates 40 to 75 during January 1996 by the Iceland radar. Occurrence histograms are also presented

with $\left|v_{\text {los }}\right| \lesssim 50 \mathrm{VHF} \mathrm{s}^{-1}$ is attributed to contamination of the ionospheric backscatter with ground backscatter. Far-range E region backscatter must be propagating by the F-E/or similar mode. This observation indicates that it cannot be assumed that all backscatter from further ranges is free of sound-speed limiting.

It is concluded that the time and range at which ionospheric backscatter is observed is a convolution of both propagation conditions and ionospheric irregularity occurrence. The propagation characteristics of HF radio waves and the ambient ionospheric electron density profile crucially determine those regions of the ionosphere that are illuminated by the radar and at which the orthogonality condition is satisfied. The absence of backscatter at a particular point within the radar field-of-view does not necessarily preclude the existence of irregularities at that location. However, this study has determined those regions of the field-of-view that are illuminated by the radars at various times of day and year, and hence where backscatter can be observed at $10 \mathrm{MHz}$. Together with an indication of the variation of backscatter occurrence as a function of radar operating frequency, such a study will help plan future operation of the radars to maximise the coverage of the field-of-view with backscatter.

\section{Frequency dependence of CUTLASS field-of-view coverage}

To determine the optimum radar operating frequency for which the field-of-view point occupancy is maxi- 
mised, the radars were operated in a swept-frequency mode on one day every month since December 1995 (27 Dec, 16 Jan, 19 Feb, 31 Mar, 9 Apr, 15 May, 14 Jun, 11 Jul, 18 Aug, 10 Sep, 15 Oct, 16 Nov). The radars stepped through 5 frequency bands (centred on approximately 10.0 MHz, $11.5 \mathrm{MHz}, 13.3 \mathrm{MHz}, 15.0 \mathrm{MHz}$, and 16.6 MHz) with each successive scan, completing a sweep of the frequency range $10 \mathrm{MHz}$ to $17 \mathrm{MHz}$ every 10 minutes. The lowest frequency band employed was equivalent to the frequency at which the other statistics data presented in this study were collected. For each day in which the swept-frequency mode was operated, the mean value of the percentage of the whole field-of-view in which ground and ionospheric backscatter occurred was determined for each frequency band. To remove the contribution from interference clutter in the higher frequency bands the data were thresholded with a signal to noise ratio of $3 \mathrm{~dB}$. The overall results of this analysis for ground and ionospheric backscatter are illustrated for the Finland and Iceland radars in Fig. 11a, c. To investigate the diurnal behaviour of ionospheric backscatter point occupancy as a function of frequency, the days were split into two time intervals approximately corresponding to daytime propagation conditions (0618 UT) and nighttime propagation conditions (00-06 UT and 18-24 UT); these results are indicated in Fig. $11 \mathrm{~b}, \mathrm{~d}$.

For both the Finland and Iceland radars the occurrence of ground backscatter decreases sharply as frequency increases. This decrease is a consequence of a decrease in the refraction of the ray paths with increasing frequency. Above a certain operating frequency, especially in winter months, refraction is insufficient to cause ionospheric reflection, penetration of the ionosphere occurs and the ground backscatter point occupancy falls to very low levels. The behaviour of the

\section{CUTLASS Finland}

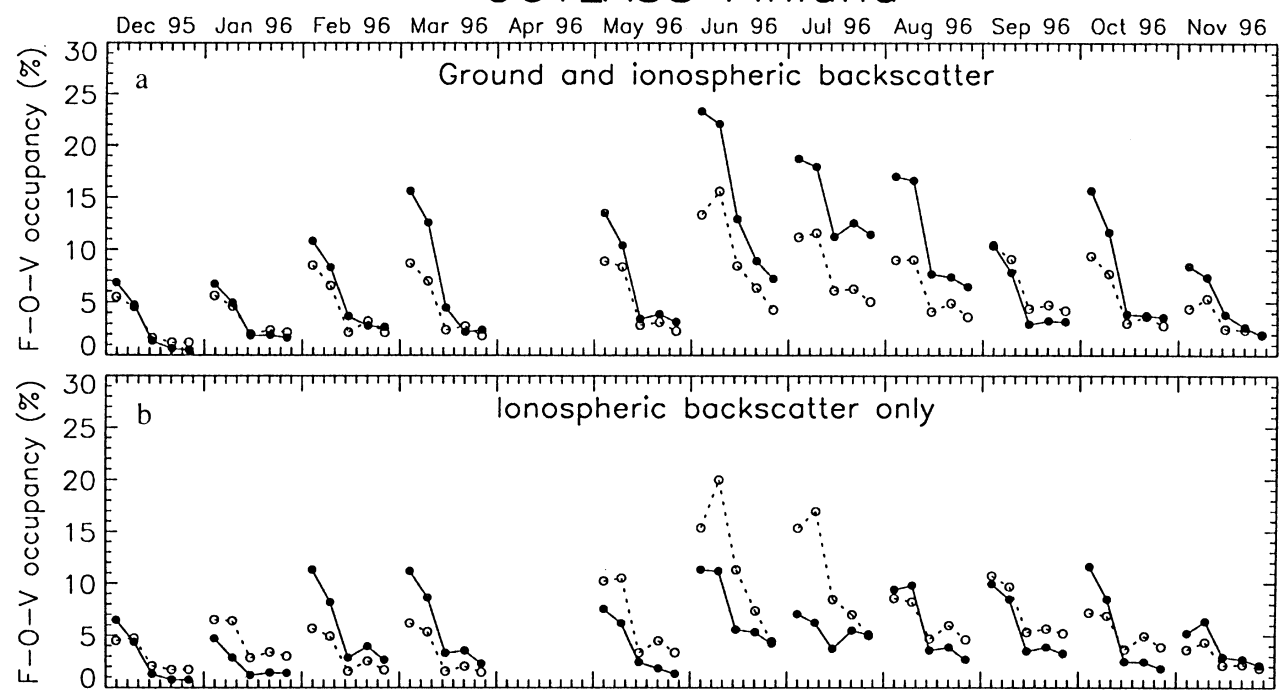

\section{CUTLASS Iceland}

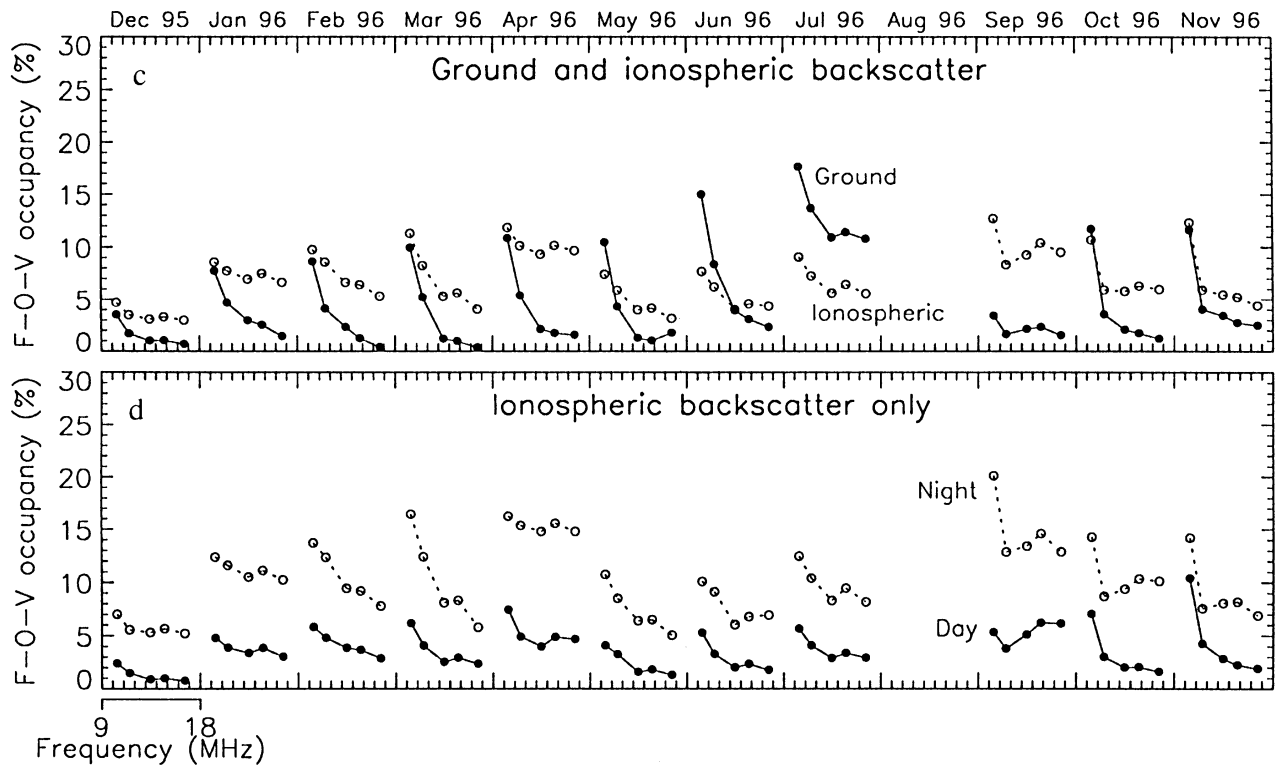

Fig. 11a-d. The variation in the occurrence of ground and ionospheric backscatter observed by the CUTLASS radars as a function of operating frequency 
Iceland radar ground backscatter for 11 July 1996 is anomalous in that the ground backscatter occurrence remained relatively high at all frequencies (see Fig. 11c). Throughout this day an intense sporadic E layer overhead of the radar produced $1 \mathrm{E}$ mode ground scatter at all frequencies; the $\mathrm{F}$ region was screened and no $1 \mathrm{~F}$ mode ground backscatter was observed.

The variation in the ionospheric backscatter point occupancy for the Finland radar follows a very similar pattern to the ground backscatter in winter months. During winter months most ionospheric backscatter observed by the Finland radar is from far ranges, propagating by the $1 \frac{1}{2} \mathrm{~F}$ mode. Above the frequency at which the $1 \mathrm{~F}$ mode no longer propagates (indicated by a sharp decrease in the ground backscatter occurrence) the far field-of-view is no longer illuminated, the $1 \frac{1}{2} \mathrm{~F}$ mode does not propagate, and the occurrence of ionospheric backscatter decreases (see Sect. 1). In summer months, most ionospheric backscatter is observed at near ranges, and consequently there is no longer such a dependence on the occurrence of ground backscatter; indeed an increase of radar frequency from $10 \mathrm{MHz}$ to $12 \mathrm{MHz}$ brought about a modest increase $(\approx 20 \%)$ in the amount of ionospheric backscatter observed at night during June and July 1996 (see Fig. 11b). Inspection of the backscatter observations for these days indicates that this increase is a consequence not so much of more favourable propagation modes being achieved with the higher frequency, but that less ground backscatter is present to obscure the ionospheric backscatter.

The occurrence of ionospheric backscatter for the Iceland radar is similar to that for Finland, decreasing in occurrence with increasing frequency. However, due to the ubiquitous presence of $\mathrm{E}$ region backscatter in the Iceland radar observations, the point occupancy does not fall to very low levels, especially during the night (Fig. 11d). The near-range E region is illuminated at all frequencies, and in a similar manner to the summer near-range ionospheric backscatter of the Finland radar, this $\mathrm{E}$ region backscatter does not rely on $\mathrm{F}$ region propagation to be observed.

An extrapolation of the observations might suggest that a decrease in frequency could increase the amount of ionospheric backscatter observed. It must be borne in mind, however, that the amount of ground backscatter would also increase, perhaps obscuring ionospheric scatter, and attenuation of HF radio waves increases dramatically below $10 \mathrm{MHz}$ due to the $f^{-2}$ dependence of non-deviative absorption in the $\mathrm{D}$ region ionosphere (e.g. Davies, 1990).

In general, $10 \mathrm{MHz}$ appears to be the optimum radar operating frequency for solar minimum conditions, though an increase in frequency to $12 \mathrm{MHz}$ during mid-summer months (especially at night) is desirable. It was suggested in Sect. 4.2 that an increase in frequency during summer months might better illuminate the Finland far-range field-of-view during the day. This does not appear to be borne out by the swept-frequency statistics, though there is more of a plateau at $10 \mathrm{MHz}$ to $12 \mathrm{MHz}$ in the daytime ionospheric point occupancy during May to August 1996 than at other times of year
(Fig. 11b). It was also suggested in Sect. 4.2, from observations of a decrease in far-range point occupancy at local noon during the winter day, that suitable frequency management might improve the amount of scatter seen. It is suggested that varying the radar operating frequency, $f$, throughout the day such that $f \approx(10 / 4) \cdot f_{0} F 2$ (where $10 \mathrm{MHz}$ is the radar operating frequency of the present study and $4 \mathrm{MHz}$ is the value of $f_{0} F 2$ for which the occurrence of ionospheric backscatter is a maximum) could improve the observation occurrence. It would appear, though, that the frequency resolution afforded by the presently available frequency bands is too coarse to implement this successfully. However, it is predicted that as ionospheric electron densities increase as solar phase progresses (see Sect. 3), the higher frequencies will be less affected by the loss of the $1 \frac{1}{2} \mathrm{~F}$ mode.

\section{Geomagnetic activity dependence of CUTLASS field-of-view coverage}

To determine the response of the backscatter occurrence to geomagnetic disturbance, the correlation between the daily mean of the field-of-view coverage of backscatter and the daily sum of the geomagnetic index $K_{\mathrm{p}}$ was determined for each month of operation of the radars. Figure 12 illustrates the monthly variation in the gradient of the least-squares fit to the data, and two scatter plots of the typical months April 1995 and January 1996 for the Finland and Iceland radars respectively. In general, for both the Finland and Iceland radars the occurrence of ground backscatter decreases markedly with increasing geomagnetic activity, especially during the months March to October. This is most probably a consequence of ionospheric storm activity, triggered by geomagnetic disturbances, causing a reduction in $f_{0} F 2$ (e.g. Prölss, 1993) and an increase in absorption leading to a decrease in ground backscatter. During the months November to February the occurrence of ground backscatter is low at all levels of geomagnetic activity and little reduction is observed during disturbed periods. The Finland radar observes a general decrease in the occurrence of ionospheric backscatter with increasing geomagnetic activity, in contrast to expectations of an increase in irregularity generation due to enhanced electric fields and precipitation in the high latitude ionosphere. The Iceland radar tends to observe an increase in the occurrence of ionospheric backscatter during disturbed periods. This difference can again be linked to the nature of the backscatter observed by the two radars, predominantly near-range $\mathrm{E}$ region in the case of Iceland and predominantly near- and far-range $F$ region in the case of Finland. The dependence of the Finland backscatter on an $\mathrm{F}$ region reflection (or refraction to near-reflection) means that once the ionosphere is disturbed, as indicated by a decrease in the occurrence of Finland ground backscatter, the orthogonality condition is more difficult to meet and the far-range $\mathrm{F}$ region is no longer illuminated by the radar, so no irregularities can be 

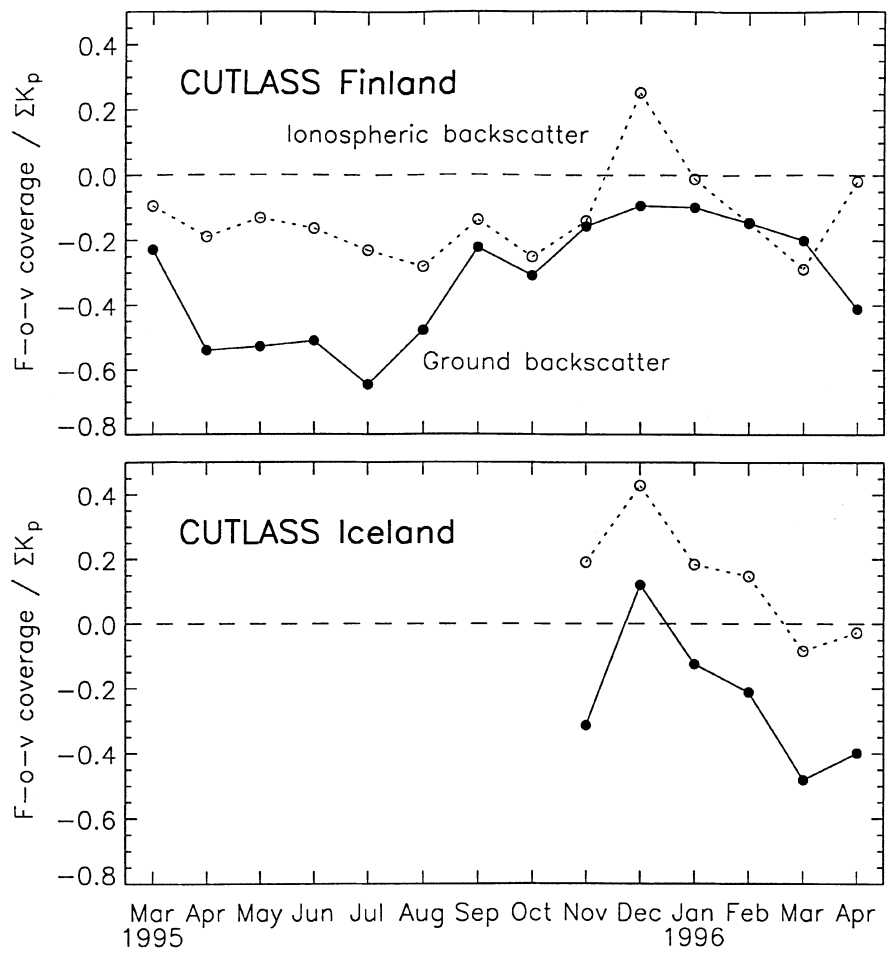

observed. The near-range $\mathrm{E}$ region, however, is illuminated by the Iceland radar at all times. Indeed, an increase in backscatter occurrence during geomagnetic activity is found with VHF radars (Waldock et al., 1985) which observe solely in the E region and are not prone to propagation degradation during disturbed periods, indicating an increase in irregularity occurrence under these conditions.

An auto-correlation analysis of the Finland field-ofview coverage with both ionospheric and ground backscatter indicates a significant 27 day periodicity, close to the solar rotation period, a phenomenon also observed with VHF radars during the declining phase of the solar cycle (Yeoman et al., 1990).

\section{Conclusions}

The observation of backscatter by high-latitude HF radars is as critically dependent on the propagation characteristics of HF radio waves in a complex and dynamic region of the ionosphere as on the presence of ionospheric irregularities themselves. The ambient ionospheric conditions, $\mathrm{E}$ and $\mathrm{F}$ region electron density, are controlled by the solar illumination of the high-latitude region. Within the polar regions, constant solar illumination during summer months and constant darkness in winter months lead to a large seasonal variation in the propagation environment. In addition, auroral features not only generate irregularities from which scatter occurs, but also strongly perturb the propagation conditions.

The location and occurrence of ionospheric backscatter, then, varies dramatically between the seasons. During summer months, ionospheric backscatter is
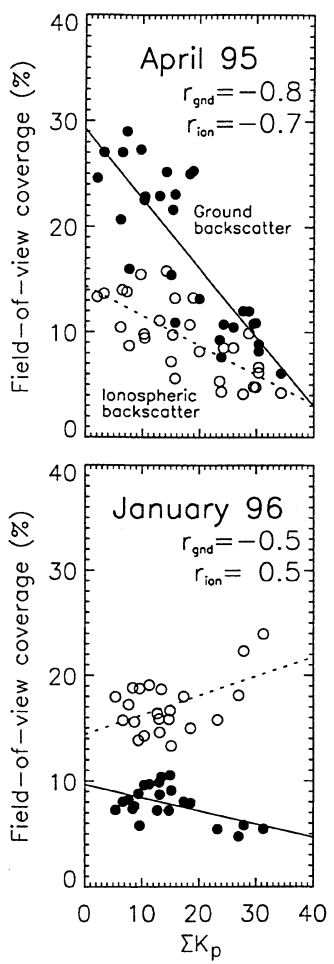

Fig. 12. right-hand panels $\mathrm{A}$ comparison of the mean daily percentage occurrence of ground (filled dots) and ionospheric (open dots) backscatter with the daily value of $\Sigma K_{\mathrm{p}}$ for the typical months April 1995 (Finland radar) and January 1996 (Iceland radar). Coefficients of correlation are indicated in the top right-hand corners. left-hand panels monthly variation of the gradient of the fit between field-ofview coverage and $\Sigma K_{\mathrm{p}}$. observed predominantly at near ranges in the midnight local time sector. During winter and equinoctial months, ionospheric backscatter occurs most frequently at far ranges in the midday local time sector. The frequency and geomagnetic activity dependence of ionospheric backscatter occurrence depends on the range at which it is observed. Far-range backscatter propagating by the $1 \frac{1}{2} \mathrm{~F}$ mode, because it depends on an $\mathrm{F}$ region reflection, is much more prone to a decrease in occurrence with an increase in frequency or geomagnetic activity. It is interesting to note that both radars differ in the amount of near-range $E$ region scatter that they observe, and in the exact behaviour with respect to operating frequency that they display, predominantly due to the different boresite azimuth of each radar (see Sect. 4.2). This indicates that care must be taken when applying the statistics of one radar to the operation of another.

It is evident that suitable frequency management should maximise the amount of backscatter observed, and indeed some SuperDARN radars already employ different frequencies for day and night ionospheric conditions. The results of Sect. 5, however, suggest that at present little improvement can be gained from such a simple scheme. In the longer term, though, Fig. 6 indicates that as solar maximum is approached, daytime values of $f_{0} F 2$, and the variation between night and day, will increase dramatically, making the choice of operating frequency much more important. It is also anticipated that the occurrence of ionospheric irregularities, and hence the observation of ionospheric backscatter, will increase towards solar maximum due to a general increase in geomagnetic activity. It is possible that evidence for such an increase in backscatter occurrence is present in the statistics already. The point occupancy 
of near-range nighttime ionospheric backscatter observed by the Finland radar is somewhat greater in May to July 1996 than in May to July 1995 (see Fig. 7a). Also the point occupancy of far-range daytime scatter appears higher in March and October 1996 than March and October 1995.

Statistical analyses of the seasonal variation of location and time of day of occurrence of backscatter, of the sort presented in the present study, facilitate future campaign planning. Studies of substorm and night-time phenomena and co-ordinated studies with the EISCAT radar are best suited to summer months. Winter months provide most scope for studying the cusp region and dayside processes. This makes possible a coordinated CUTLASS and optical study of the cusp as Svalbard $\left(78^{\circ} \mathrm{N}, 18^{\circ} \mathrm{E}\right.$ geographic coordinates, near summary points 10 and 11 for both radars, see Fig. 2) is approximately co-located with the cusp at local noon and is in darkness throughout the day around winter solstice.

Acknowledgements. CUTLASS is supported by PPARC, the Swedish Institute for Space Physics, Uppsala, and the Finnish Meteorological Institute. The Tromsø dynasonde data were provided by Mike Reitveld and the EISCAT Scientific Association. We would like to thank Darren Wright of the University of Leicester for assistance with the analysis of the dynasonde data. The Sodankylä ionosonde data were provided by the Sodankylä Geophysical Observatory.

Topical Editor D. Alcaydé thanks J.-P. Cerisier and J. M. Ruohoniemi for their help in evaluating this paper.

\section{References}

Baker, K. B., and S. Wing, A new magnetic coordinate system for conjugate studies at high latitudes, J. Geophys. Res., 94, 91399143, 1989.

Bowline, M. D., J. J. Sojka, and R. W. Schunk, Relationship of theoretical patch climatology to polar cap patch observation, Radio Sci., 31, 635-644, 1996.

Buneman, O., Excitation of field-aligned sound waves by electron streams, Phys. Rev. Lett., 10, 285-287, 1963.

Carlson, H. C., The dark polar ionosphere: progress and future challenges, Radio Sci., 29, 157-165, 1994.

Davies, K., A nomenclature for oblique ionospheric soundings and ray tracing, Radio Sci., 2, 1395-1396, 1967.

Davies, K., Ionospheric Radio, Peter Peregrinus Ltd., London, 1990.

Farley, D. T., A plasma instability resulting in field-aligned irregularities in the ionosphere, J. Geophys. Res., 63, 60836097, 1963.

Fejer, B. G., and M. C. Kelley, Ionospheric irregularities, Rev. Geophys. Space Phys., 18, 401, 1980.

Fejer, B. G. and J. F. Providakes, High-latitude E-region irregularities: new results, Phys. Scripta, T18, 167-178, 1987.

Feldstein, Y. I., and G. V. Starkov, Dynamics of auroral belt and polar geomagnetic disturbances, Planet. Space Sci., 15, 209 230, 1967.

Greenwald, R. A., W. Weiss, E. Nielsen, and N. R. Thomson, STARE: a new radar auroral backscatter experiment in northern Scandinavia, Radio Sci., 13, 1021-1039, 1978.

Greenwald, R. A., K. B. Baker, J. R. Dudeney, M. Pinnock, T. B. Jones, E. C. Thomas, J.-P. Villain, J.-C. Cerisier, C. Senior, C. Hanuise, R. D. Hunsucker, G. Sofko, J. Koehler, E. Nielsen, R. Pellinen, A. D. M. Walker, N. Sato, and H. Yamagishi, DARN/
SuperDARN: a global view of the dynamics of high-latitude convection, Space Sci. Rev., 71, 761-796, 1995.

Haldoupis, C., A review on radio studies of auroral E-region ionospheric irregularities, Ann. Geophysicae, 7, 239-258, 1988.

Haldoupis, C., and K. Schlegel, A 50-MHz radio Doppler experiment for midlatitude $E$ region coherent backscatter studies: system description and first results, Radio Sci., 28, 959-978, 1993.

Haldoupis, C., A. Bourdillon, M. Six, and J. Delloue, Midlatitude $E$ region coherent backscatter observed simultaneously at two HF radar frequencies, J. Geophys. Res., 101, 7961-7971, 1996.

Hanuise, C., J. P. Villain, D. Gresillon, B. Cabrit, R. A. Greenwald, and K. B. Baker, Interpretation of HF radar ionospheric Doppler spectra by collective wave scattering theory, Ann. Geophysicae, 11, 29-39, 1993.

Holzworth, R. H., and C.-I. Meng, Mathematical representation of the auroral oval, Geophys. Res. Lett., 2, 377-380, 1975.

Kelley, M. C., J. F. Vickrey, C. W. Carlson, and R. Torbert, On the origin and spatial extent of high latitude $\mathrm{F}$ region irregularities, J. Geophys. Res., 87, 4469-4475, 1982.

Leonard, J. M., M. Pinnock, A. S. Rodger, J. R. Dudeney, R. A. Greenwald, and K. B. Baker, Ionospheric plasma convection in the Southern Hemisphere, J. Atmos. Terr. Phys., 57, 889-897, 1995.

Milan, S. E., T. B. Jones, T. R. Robinson, E. C. Thomas, T. K. Yeoman, Interferometer evidence for the observation of ground backscatter from behind the CUTLASS radars, Ann. Geophysicae, 15, 29-39, 1997.

Nielsen, E., and K. Schlegel, A first comparison of STARE and EISCAT electron drift velocity measurements, J. Geophys. Res., 90, 3495-3504, 1983

Nielsen, E., W. Güttler., E. C. Thomas, C. P. Stewart, T. B. Jones, and A. Hedberg, A new radar auroral backscatter experiment, Nature, 304, 712-714, 1983a.

Nielsen, E., J. D. Whitehead, L. A. Hedberg, and T. B. Jones, A test of the cosine relationship using three-radar velocity measurements, Radio Sci., 18, 230, 1983b.

Ossakow, S. L., and P. K. Chaturvedi, Current convective instability in the diffuse aurora, Geophys. Res. Lett., 6, 323-334, 1979.

Prölss, G. W., On explaining the local time variation of ionospheric storm effects, Ann. Geophysicae, 11, 1-9, 1993.

Robinson, T R., Towards a self-consistent non-linear theory of radar auroral backscatter, J. Atmos. Terr. Phys., 48, 417-422, 1986.

Robinson, T. R., A. J. Stocker, and G. Bond, HF Backscatter from artificial irregularities above Tromsø, Colloquium on " $H F$ antennas and propagation", IEE, 9/1-9/7, 1995.

Rodger, A. S., and A. C. Graham, Diurnal and seasonal occurrence of polar patches, Ann. Geophysicae, 14, 533-537, 1996.

Ruohoniemi, J. M., and R. A. Greenwald, Observations of IMF and seasonal effects in high-latitude convection, Geophys. Res. Lett., 22, 1121-1124, 1995.

Ruohoniemi, J. M., and R. A. Greenwald, Statistical patterns of high-latitude convection obtained from Goose Bay HF radar observations, J. Geophys. Res., 101, 21743-21763, 1996.

Ruohoniemi, J. M., R. A. Greenwald, K. B. Baker, J. P. Villain, and M. A. McCready, Drift motions of small-scale irregularities in the high-latitude F region: an experimental comparison with plasma drift motions, J. Geophys. Res., 92, 4553-4564, 1987.

Sudan, R. N., Unified theory of Type I and Type II irregularities in the equatorial electrojet, J. Geophys. Res., 88, 4853-4860, 1983.

Sudan, R. N., J. Akinrimisi, and D. T. Farley, Generation of small-scale irregularities in the equatorial electrojet, J. Geophys. Res., 78, 240-248, 1973.

Tsunoda, R. T., High-latitude F region irregularities: a review and synthesis, Rev. Geophys., 26, 719-760, 1988.

Villain, J. P., G. Caudal, and C. Hanuise, A SAFARI-EISCAT comparison between the velocity of $\mathrm{F}$ region small-scale irregularities and the ion drift, J. Geophys. Res., 90, 84338443, 1985. 
Waldock, J. A., T. B. Jones, and E. Nielsen, Statistics of 1-m wavelength plasma irregularities and convection in the auroral E region, Radio Sci., 20, 709-717, 1985.

Weber, E. J., J. Buchau, J. G. Moore, J. R. Sharber, R. C. Livingstone, J. D. Winningham, and B. W. Reinisch, F layer ionisation patches in the polar cap, J. Geophys. Res., 89, 16831694, 1984.
Yeoman, T. K., M. D. Burrage, M. Lester, T. R. Robinson, and T. B. Jones, Long-term variation of radar-auroral backscatter and the interplanetary sector structure, J. Geophys. Res., 95, 21123 21132, 1990. 